NBER WORKING PAPER SERIES

\title{
VENTURE CAPITAL CONTRACTING AND \\ SYNDICATION: AN EXPERIMENT IN \\ COMPUTATIONAL CORPORATE FINANCE
}

\author{
Zsuzsanna Fluck \\ Kedran Garrison \\ Stewart C. Myers \\ Working Paper 11624 \\ http://www.nber.org/papers/w11624 \\ NATIONAL BUREAU OF ECONOMIC RESEARCH \\ 1050 Massachusetts Avenue \\ Cambridge, MA 02138 \\ September 2005
}

We are grateful for helpful comments from Ulf Axelson, Amar Bhide, Francesca Cornelli, Paul Gompers, Steve Kaplan, Josh Lerner, Tom Noe, David Scharfstein, Per Str;§omberg, Michael Weisbach and participants at presentations at LSE, MIT, Michigan State University, the University of Minnesota, the Conference on Venture Capital and Private Equity (Stockholm), the Financial Intermediation Research Society Conference (Capri) and the American Finance Association meetings (Philadelphia). The views expressed herein are those of the author(s) and do not necessarily reflect the views of the National Bureau of Economic Research.

(C2005 by Zsuzsanna Fluck, Kedran Garrison and Stewart C. Myers. All rights reserved. Short sections of text, not to exceed two paragraphs, may be quoted without explicit permission provided that full credit, including () notice, is given to the source. 
Venture Capital Contracting and Syndication: An Experiment in Computational Corporate Finance

Zsuzsanna Fluck, Kedran Garrison and Stewart C. Myers

NBER Working Paper No. 11624

September 2005

JEL No. G24, G32

\section{$\underline{\text { ABSTRACT }}$}

This paper develops a model to study how entrepreneurs and venture-capital investors deal with moral hazard, effort provision, asymmetric information and hold-up problems. We explore several financing scenarios, including first-best, monopolistic, syndicated and fully competitive financing. We solve numerically for the entrepreneur's effort, the terms of financing, the venture capitalist's investment decision and NPV. We find significant value losses due to holdup problems and underprovision of effort that can outweigh the benefits of staged financing and investment. We show that a commitment to later-stage syndicate financing increases effort and NPV and preserves the option value of staged investment. This commitment benefits initial venture capital investors as well as the entrepreneur.

Zsuzsanna Fluck

Michigan State University

Department of Finance

Graduate School of Management

315 Eppley Center

East Lansing, MI 48824-1122

fluck@bus.msu.edu

Kedran Garrison

MIT - EFA

77 Massachusetts Avenue

Cambridge, MA 02139-4307

garrisk@mit.edu
Stewart C. Myers

Sloan School of Management

MIT, Room E52-451

50 Memorial Drive

Cambridge, MA 02142-1347

and NBER

scmyers@mit.edu 


\section{Introduction}

This paper develops a model to study how entrepreneurs and venture-capital investors deal with effort provision, moral hazard, asymmetric information and hold-up problems when contracts are incomplete and investment proceeds in stages. How much value is lost in the entrepreneur-venture capital relationship relative to first-best value? How does the value lost depend on risk and the time-pattern of required investment? What determines whether a positive-NPV project can in fact be financed? What are the advantages and disadvantages of staged financing? Are there significant efficiency gains from syndication of later-stage financing?

We argue that these and related questions should not be analyzed one by one, but jointly in a common setting. Some features of venture-capital contracting may not solve a particular problem, but instead trade off one problem against another. For example, a study that focused just on the option-like advantages of staged investment could easily miss the costs of staging, particularly the negative feedback to effort if venture-capital investors can hold up the entrepreneur by dictating financing terms in later stages. (We find many cases where hold-up costs outweigh the advantages of staged financing and full upfront financing actually increases value.)

A joint analysis of the problems inherent in the entrepreneur-venture capital relationship does not lead to closed-form solutions or simple theorems. Therefore we embark on an experiment in computational corporate finance, which is the formal study of financing and investment problems that do not have closed-form solutions. ${ }^{1}$ We believe the time is ripe for a computational model of venture capital. Venture-capital institutions, contracts and procedures were well documented more than a decade ago. It was clear then that the agency and information problems encountered in ordinary financing decisions are especially acute in venture capital. The successes of venture capital have stimulated theoretical work on how these problems are mitigated. But most theoretical papers have focused on only one problem or tradeoff and run the risk of missing the bigger picture.

Of course the breadth and richness of a computational model do not come free, and numerical results are never absolutely conclusive. One can never rule out the possibility that results would have been different with different inputs or modeling choices. But our model, though simplified, follows actual practice in venture capital. We have verified our main results over a wide range of inputs. We believe our results help to clarify why venturecapital investment works when it works and why it sometimes fails.

The structure of venture-capital financing is known from many sources, including Sahlman (1990), Lerner (1994), Fenn, Liang and Prowse (1995), Gompers (1995), Gompers and Lerner (1996, 2002), Hellman and Puri (2000, 2002) and Kaplan and Strömberg (2003). We will preview our model and results after a brief review of the features of venture-capital contracting that are most important to our paper. The review includes comments on related

\footnotetext{
${ }^{1}$ Computational models are frequently used to understand the value of real and financial options, but their use on the financing side of corporate balance sheets is an infant industry. The short list of computational papers on financing includes Mello and Parsons (1992), Leland (1994, 1998), Boyd and Smith (1994), Parrino and Weisbach (1999), Robe (1999, 2001), Parrino, Poteshman and Weisbach (2002) and Ju, Parrino, Poteshman and Weisbach (2004). These papers explore the tradeoff theory of capital structure and the risk-shifting incentives created by debt financing.
} 
theoretical work.

\section{$1.1 \quad$ Venture capital contracting}

Venture capital brings together one or more entrepreneurs, who contribute ideas, plans, human capital and effort, and private investors, who contribute experience, expertise, contacts and most of the money. For simplicity, we will refer to one entrepreneur and to one initial venture-capital investor. Their joint participation creates a two-way incentive problem. The investor has to share financial payoffs with the entrepreneur in order to secure her commitment and effort. Thus the investor may not be willing to participate even if the startup has positive overall NPV. Second, the entrepreneur will underinvest in effort if she has to share her marginal value added with the investor. ${ }^{2}$

\subsubsection{Sweat equity}

The entrepreneur invests even when she puts up none of the financing. She contributes her effort and absorbs part of the firm's business risk. The difference between her salary and her outside compensation is an opportunity cost. Specialization of her human capital to the new firm also creates an opportunity cost if the firm fails. ${ }^{3}$

The entrepreneur receives shares in exchange for these investments. These shares may not vest immediately, and they are illiquid unless and until the firm is sold or goes public. ${ }^{4}$ The venture capitalist frequently requires the entrepreneur to sign a contract that precludes work for a competitor. The entrepreneur therefore has a strong incentive to stick with the firm and make it successful. In our model, the entrepreneur contributes no financial investment and is willing to continue so long as the present value of her shares exceeds her costs of effort.

\subsubsection{Staged investment and financing}

A startup is a compound call option. Financing and investment are made in stages. The stages match up with business milestones, such as a demonstration of technology or a successful product introduction.

We assume that the entrepreneur and venture capitalist cannot write a complete contract to specify the terms of future financing. The terms are determined by bargaining as financing is raised stage by stage. If additional investors join in later stages, the bargain has to be acceptable to them as well as the entrepreneur and initial venture capitalist.

The option value added by staging is obvious, but staging may also serve other purposes. In Bergemann and Hege (1998) and Nöldeke and Schmidt (1998), staging allows the venture capitalist to learn the startup's value and thereby induce the entrepreneur's effort. In Neher

\footnotetext{
${ }^{2}$ This is an extreme version of Myers's (1977) underinvestment problem.

${ }^{3}$ This opportunity cost could perhaps be reduced if new ventures are developed as divisions of larger firms. See Gromb and Scharfstein (2003) and Gompers, Lerner and Scharfstein (2003).

${ }^{4}$ Employees typically receive options that vest gradually as employment continues and the startup survives. But our entrepreneur is a founder, not an employee hired later. Founders typically receive shares, not options. The entrepreneur's shares are fully vested, but additional shares may be granted later. See Kaplan and Strömberg (2003).
} 
(1996) and Landier (2002), the venture capitalist's ability to deny financing at each stage forces the entrepreneur to exert higher effort and prevents her from diverting cash flows.

Venture capital investors usually buy convertible preferred shares. If the firm is shut down, the investors have a senior claim on any remaining assets. The shares convert to common stock if the firm is sold or taken public. ${ }^{5}$ Ordinary debt financing is rarely used, although we will consider whether debt could serve as an alternative source of financing.

\subsubsection{Control}

The venture capitalist does not have complete control of the new firm. For example, Kaplan and Strömberg (2003, Table 2) find that venture-capital investors rarely control a majority of the board of directors. But Kaplan and Strömberg also find that venture capitalists' control increases when the firm's progress is unsatisfactory.

Staged financing can give incumbent venture capitalists effective control over access to financing. Their refusal to participate in the second or later rounds of financing would send a strong negative signal to other potential investors and probably deter them from investing. ${ }^{6}$ In practice, the incumbents' decision not to participate is usually a decision to shut down the firm.

Giving venture capitalists effective veto power over later-stage investment is in some respects efficient. The decision to shut down or continue cannot be left to the entrepreneur, who is usually happy to continue investing someone else's money as long as there is any chance of success. The venture capitalist is better equipped to decide whether to exercise each stage of the compound call option.

Thus staged financing has a double benefit, at least for the venture capitalist. It can block the entrepreneur's incentive to continue and it allows the venture capitalist to exploit the startup's real-option value. But it is also costly if the venture capitalist can use the threat of shutdown to hold up the entrepreneur and dilute her stake. Anticipated dilution feeds back into the entrepreneur's incentives and effort and reduces overall value. This is the holdup problem of staged financing. For a wide range of parameter values we find that the holdup problem is so severe that the venture capitalist is better off abandoning staged financing and providing all financing upfront. When later financing stages are syndicated on competitive terms, however, staged financing is always more efficient than full upfront financing. We will also show that the holdup problem cannot be solved simply by substituting debt for equity financing. When contracts are incomplete, stage by stage bargaining enables the incumbent venture capitalist to extract surplus regardless of the form of financing.

Most prior theory assumes that venture-capital investors retain residual rights of control. The venture capitalist's rights to decide on investment (Aghion and Bolton (1992)) and to replace the entrepreneur (Fluck (1998), Hellman (1998), Myers (2000), Fluck (2001)) play an important role in enforcing financial contracts between investors and entrepreneurs. The

\footnotetext{
${ }^{5}$ The use of convertible securities in venture capital is analyzed in Green (1984), Berglof (1994), Kalay and Zender (1997), Repullo and Suarez (1998), Cornelli and Yosha (2003), Schmidt (2003) and Winton and Yerramilli (2003).

${ }^{6}$ The role of the monopolist financier was investigated in Rajan (1992), Petersen and Rajan (1994) and Cestone wand White (2004).
} 
entrepreneur's option to reacquire control and realize value in an initial public offering is a key incentive in Black and Gilson (1998), Myers (2000) and Aghion, Bolton and Tirole (2001).

\subsubsection{Syndication of later-stage financing}

Later-stage financing usually comes from a syndicate of incumbent and new venture-capital investors. We show how a commitment to syndicate can alleviate the holdup problem by assuring the entrepreneur more favorable terms in later rounds of financing. This encourages effort in all periods, which increases overall value.

Syndication of venture capital investments has been explained in several other ways. It is one way to gather additional information about a startup's value - see, for example, Gompers and Lerner (2002, Ch. 9) and Sah and Stiglitz (1986). Wilson (1968) attributes syndication to venture capitalists' risk aversion. Syndication may also reflect tacit collusion: early investors syndicate later rounds of financing, and the syndication partners return the favor when they develop promising startups (Pichler and Wilhelm (2001)). In Cassamatta and Haritchabalet (2004), venture capitalists acquire different skills and experience and syndication pools their expertise. We offer a different rationale: syndication can protect the entrepreneur from ex post holdup by investors and thereby encourage effort.

\subsubsection{Exit}

Entrepreneurs can rely on venture capitalists to cash out of successful startups. Venture capital generally comes from limited-life partnerships, and the partners are not paid until the startups are sold or taken public. Myers (2000) shows that venture capitalists would cash out voluntarily in order to avoid the adverse incentives of long-term private ownership.

Chelma, Habib and Lyngquist (2002) consider how the various provisions of venturecapital contracts are designed to mitigate multiple agency and information problems. Their paper focuses on exit provisions and does not consider syndication.

\subsection{Preview of the model and results}

We aim to capture the most important features of venture capital. For simplicity we assume two stages of financing and investment at dates 0 and 1. If successful, the firm is sold or taken public at date 2 , and the entrepreneur and the investors cash out. The entrepreneur and the investors are risk-neutral NPV maximizers, although the entrepreneur's NPV is net of the costs of her effort.

We value the startup as a real option. The underlying asset is the potential market value of the firm, which we assume is lognormally distributed. But full realization of potential value requires maximum effort from the entrepreneur at dates 0 and 1 . The entrepreneur's effort is costly, so her optimal effort is less than the maximum and depends on her expected share of the value of the firm at date 2 . The venture capitalist and the entrepreneur negotiate ownership percentages at date 0 , but these percentages change at date 1 when additional financing is raised and invested. 
We assume that the firm cannot start or continue without the entrepreneur. If financing cannot be arranged on terms that satisfy her participation constraints, no investment is made and the firm shuts down. The venture capitalist's date- 0 and date- 1 participation constraints must also be met, since he will not invest if his NPV is negative.

The efficiency of venture-capital investment hinges on the nature and terms of financing. We compare six cases.

1. First-best. If the entrepreneur could finance the startup out of her own pocket, she would maximize overall value, net of the required financial investments and her costs of effort. First-best is our main benchmark for testing the efficiency of other cases.

2. Fully competitive. In this case, financing is available on competitive terms $(\mathrm{NPV}=0)$ at both date 0 and date 1 , which gives the highest possible value when the entrepreneur must raise capital from outside investors. We include this case as an alternative benchmark to first-best.

3. Monopoly, staged investment. Here the initial venture capitalist can dictate the terms of financing at dates 0 and 1 and can hold up the entrepreneur at date $1 .{ }^{7}$ The venture capitalist does not squeeze the last dollar from the entrepreneur's stake, however. He squeezes just enough in each period to maximize the present value of his shares.

4. Monopoly, no staging. In this case, the venture capitalist commits all necessary funds at date 0 and lets the entrepreneur decide whether to continue at date 1 . This means inefficient investment decisions at date 1 , because the entrepreneur is usually better off continuing, even when the odds of success are low and overall NPV is negative. But effort increases at both date 0 and date 1 , because the venture capitalist can no longer control the terms of later-stage financing. This case helps clarify the tradeoff between the real-option value of staged investment and the under-provision of effort because of the holdup problem.

5. Syndication. In this case a syndicate of additional investors joins the original venture capitalist at date 1 . We assume that the syndicate financing comes on more competitive terms than in the monopoly case, for simplicity we will focus on the fully competitive case $(\mathrm{NPV}=0)$. Syndication mitigates the holdup problem, increasing the entrepreneur's effort and overall NPV.

6. Debt. Venture capitalists rarely finance startups with ordinary debt, but we nevertheless consider debt financing briefly as an alternative. Debt financing effectively gives the entrepreneur a call option on the startup's final value at date 2 .

We assume that the initial venture capitalist and the entrepreneur are equally informed about potential value, although potential value is not verifiable and contractible. But financing terms in the syndication case depend on the information available to new investors. We start by assuming complete information, but also consider asymmetric information and explore whether the terms of the incumbent venture capitalist's participation in date- 1 financing could reveal the incumbent's inside information.

\footnotetext{
${ }^{7}$ This would be the case if the venture capitalist decided that certain non-verifiable performance milestones had not been met.
} 
We solve the model for each financing case over a wide range of input parameters, including the potential value of the firm, the variance of this value, the amount and timing of required investment and the marginal costs and payoffs of effort. We report a representative subset of results in Table 1 and Figures 3 through 10. Results are especially sensitive to the marginal costs and payoffs of effort, so we vary these parameters over very wide ranges. Our main results include the following:

1. We find economically significant value losses, relative to first best, even when the dollarequivalent cost of effort is a small fraction of required financial investment. Thus many startups with positive NPVs cannot be financed. Value losses decline as the marginal benefit of effort increases or the marginal cost declines.

2. Value losses are especially high in the monopoly case with staged investment, where the incumbent venture capitalist can dictate the terms of financing at date 1 . For a wide range of parameter values, both the venture capitalist and entrepreneur are better off in the no-staging case with full upfront financing. That is, the costs of the no-staging case (inefficient investment at date 1) can be less than the value loss due to under-provision of effort in the monopoly, staged financing case.

3. Syndicate financing at date 1 increases effort and the date- 0 NPVs of both the entrepreneur and the initial venture capitalist. The venture capitalist is better off than in the monopoly case, despite taking a smaller share of the venture. Moreover, staged financing with syndication always produces higher overall values than the no-staging case. The combination of staged financing and later-stage syndication dominates the alternative of giving the entrepreneur all the money upfront.

4. Syndicate financing is most effective when new investors are fully informed. The incumbent venture capitalist may be able to reveal his information through his participation in date-1 financing. However, the fixed-fraction participation rule derived by Admati and Pfleiderer (1994) does not achieve truthful information revelation in our model, because the terms of financing effect the entrepreneur's effort. The fixed-fraction rule would lead the venture capitalist to over-report the startup's value: the higher the price paid by new investors, the more the entrepreneur's existing shares are worth, and the harder she works. The incumbent venture capitalist captures part of the gain from her extra effort. A modified fixed-fraction rule works in some cases, however. With the modified rule, the incumbent's fractional participation increases as the reported value increases.

5. We expected venture-capital contracting to be more efficient for high-variance investments, but that is not generally true. Increasing the variance of potential value sometimes increases value losses, relative to first best, and sometimes reduces them, depending on effort parameters and the financing case assumed.

6. Debt financing does not solve the holdup problem, because the venture capitalist can still squeeze the entrepreneur by demanding a high interest rate on debt issued at date 1. Debt financing is more efficient in some cases but not generally. Debt can improve the entrepreneur's incentives at later financing stages, but many startups that can be financed with equity cannot raise financing by issuing debt. Switching from equity to 
debt financing does add value in some cases, but not generally. In most cases, syndicate financing with equity rather than debt increases both overall NPV and the NPV to the original venture capitalist.

We recognize that we have left out several aspects of venture capital that could influence our results. First, we ignore risk aversion. The venture capitalist and entrepreneur are assumed risk-neutral. This is reasonable for venture capitalists, who have access to financial markets. ${ }^{8}$ It is less reasonable for entrepreneurs, who can't hedge or diversify payoffs without damaging incentives. ${ }^{9}$

Second, we do not explicitly model the costs and value added of the venture capitalist's effort. We are treating his effort as a cost sunk at startup and fixed afterwards. In effect, we assume that if the venture capitalist decides to invest, he will exert appropriate effort, and that the cost of this effort is rolled into the required investment.

Third, we assume that final payoffs to the entrepreneur and venture-capital investors depend only on the number of shares bargained for at dates 0 and 1 . We do not explicitly model the more complex, contingent contracts observed in some cases by Kaplan and Strömberg (2003) ${ }^{10}$ and we do not attempt to derive the optimal financial contracts for our model setup. However, our results in Section 4 suggest that the use of contingent share awards may facilitate truthful revelation of information by the initial venture capitalist to members of a later-stage financing syndicate.

Finally, we do not model the search and screening processes that bring the entrepreneur and venture capitalist together in the first place. The costs and effectiveness of these processes could affect the terms of financing. ${ }^{11}$ For example, if an entrepreneur's search for alternative financing would be cheap and quick, the initial venture capitalist's bargaining power is reduced. Giving the entrepreneur the option to search for another initial investor would not change the structure of our model, however. It would simply tighten the entrepreneur's participation constraint at date 0 and thereby reduce the intial venture capitalist's bargaining power.

The rest of this paper is organized as follows. Section 2 sets up our model and solves the first-best case. Section 3 covers monopoly financing with and without staging. Section 4 covers the syndication and fully competitive cases. Numerical results are summarized and interpreted in Section 5. Section 6 briefly considers debt financing. Section 7 sums up our conclusions and notes questions remaining open for further research.

\footnotetext{
${ }^{8}$ Of course, the venture capitalist will seek an expected rate of return high enough to cover the market rate of risk in the startup. The payoffs in our model can be interpreted as certainty equivalents.

${ }^{9}$ Perhaps the entrepreneur's risk aversion is cancelled out by optimism. See Landier and Thesmar (2003).

${ }^{10}$ Kaplan and Strömberg (2003, Table 3) find contingent contracts in $73 \%$ of the financing rounds in their sample. The most common contingent contract depends on the founding entrepreneur staying with the firm, for example a contract requiring the entrepreneur's shares to vest. Vesting is implicit in our model, because the entrepreneur gets nothing if the firm is shut down at date 1 . Contingent contracts are also triggered by sale of securities, as in IPOs, or by default on a dividend or redemption payment. But solving the incentive and moral hazard problems in our model would require contracts contingent on effort or interim performance, which are non-verifiable in our model. Such contracts are rare in Kaplan and Strömberg's sample.

${ }^{11}$ Inderst and Muller (2003) present a model of costly search and screening, with bargaining and endogenous effort by both the entrepreneur and the venture capitalist. Their model does not consider staged investment and financing.
} 


\section{Model Setup and the First-Best Case}

The entrepreneur possesses a startup investment opportunity that requires investments $I_{0}$ and $I_{1}$ at dates 0 and 1 . If both investments are made, the startup continues to date 2 and the final value of the firm is realized.

If the investment at date 1 is not made, or if the entrepreneur refuses to participate, the startup is shut down and liquidated. We assume for simplicity that liquidation value is zero. (It is typically small for high-tech startups.) This assumption simplifies our analysis of financing, because the venture capitalist's preferred shares have value only if converted. Thus, we can treat these shares as if they were common in the first place.

The total payoff at date 2 is $P$, which is stochastic and depends on the entrepreneur's effort at time 0 and time $1, x_{0}$ and $x_{1}$, and on $V_{2}$, the potential value of the firm at date 2 . Effort affects the payoff multiplicatively through the effort functions $f_{0}\left(x_{0}\right)$ and $f_{1}\left(x_{1}\right)$ :

$$
P=f_{0} f_{1} V_{2}
$$

Effort generates positive but decreasing returns, that is, $f(0)=0, f>0$ and $f^{\prime \prime}<0$. The entrepreneur bears the costs of her effort, $g_{0}\left(x_{0}\right)$ and $g_{1}\left(x_{1}\right)$. The effort cost function is strictly increasing and convex, that is, $g(0) \geq 0, g^{\prime}>0$ and $g^{\prime \prime}>0$.

The potential value $V_{2}$ is the sole source of uncertainty. We define the expected value $E_{1}\left(V_{2}\right)$ at date 1 as $V_{1}$ and expected value $E_{0}\left(V_{2}\right)$ at date 0 as $V_{0}$. The expected payoffs at dates 0 and 1 , assuming that the firm will survive until date 2, are:

$$
\begin{aligned}
& E_{1}(P)=E_{1}\left(f_{0} f_{1} V_{2}\right)=f_{0} f_{1} E_{1}\left(V_{2}\right)=f_{0} f_{1} V_{1} \\
& E_{0}(P)=E_{0}\left(E_{1}(P)\right)=f_{0} E_{0}\left(f_{1} V_{1} \mid V_{0}\right)
\end{aligned}
$$

where $E_{0}\left(f_{1} V_{1} \mid V_{0}\right)$ is an integral that accounts for the dependence of $f_{1}$ on $V_{1}$. We assume risk-neutrality and a risk-free interest rate of zero. We use lognormal probability distributions for $V_{1}$ and $V_{2}$, with standard deviation $\sigma$ per period.

Define the effort function $f$ and the effort cost function $g$ as

$$
\begin{aligned}
f_{t} & =1-e^{-\theta_{f} x_{t}} \\
g_{t} & =e^{\theta_{g} x_{t}}
\end{aligned}
$$

for $t=0,1$. The effort function $f$ asymptotes to 1 , so we interpret $V_{1}$ and $V_{2}$ as maximum attainable values as $x \rightarrow \infty$. The degree of concavity and convexity of $f$ and $g$ depends on $\theta_{f}$ and $\theta_{g}$. The effort functions are plotted in Figure 1 for several values of $\theta_{f}$ and $\theta_{g}$.

The timeline of the financing process is as follows:

\begin{tabular}{lll}
\hline $\mathbf{t}=\mathbf{0}$ & $\mathbf{t}=\mathbf{1}$ & $\mathbf{t}=\mathbf{2}$ \\
$V_{0}$ known & $V_{1}$ realized & $V_{2}$ realized \\
$\alpha_{0}^{C}$ determined & $\alpha_{1}^{C}$ determined & $P=f_{0} f_{1} V_{2}$ \\
$I_{0}, x_{0}^{*}$ invested if $N P V_{0}^{M} \geq 0$ & $I_{1}, x_{1}^{*}$ invested if $N P V_{1}^{M} \geq 0$ & \\
& and $N P V_{0}^{C} \geq 0$ & and $N P V_{1}^{C} \geq 0$
\end{tabular}


First, the entrepreneur $(M)$ goes to the initial venture capitalist $(C)$ to raise startup financing. If he is willing to invest, then she and he negotiate the initial ownership shares $\alpha_{0}^{M}$ and $\alpha_{0}^{C}$. At date $1, V_{1}$ is observed and there is another round of bargaining over the terms of financing. If the initial venture capitalist also supplies all financing at date 1 , then he can dictate the terms and his share becomes $\alpha_{1}^{C}$, with a corresponding adjustment in $\alpha_{1}^{M}$. If the initial venture capitalist brings in a syndicate of new investors at date 1 , then the syndicate receives an ownership share of $\alpha_{1}^{S}$, and $\alpha_{1}^{M}$ and $\alpha_{1}^{C}$ adjust accordingly. The terms of financing are fixed after date 1.

\section{$2.1 \quad$ First-best}

In the first-best case, the entrepreneur supplies all of the money, $I_{0}+I_{1}$, and owns the firm $\left(\alpha_{0}^{M}=\alpha_{1}^{M}=1\right)$. The entrepreneur maximizes NPV net of her costs of effort. If she decides to invest, she expends the optimal efforts $x_{0}^{\star}$ and $x_{1}^{\star}$.

The entrepreneur has a compound real call option. The exercise price at date 1 is endogenous, however, because it includes the cost of effort, and effort depends on the realized potential value $f_{0} V_{1}$. Since we use the lognormal, our solutions will resemble the BlackScholes formula, with extra terms capturing the cost of effort.

We now derive the first-best investment strategy, solving backwards. Details of this and subsequent derivations are in the Appendix. By date 1, the entrepreneur's date-0 effort and investment are sunk. Her date-1 NPV is

$$
N P V_{1}^{M}=\max \left[0, \max _{x_{1}}\left(f_{0} f_{1}\left(x_{1}\right) V_{1}-g_{1}\left(x_{1}\right)-I_{1}\right)\right]
$$

The first-order condition for effort is $f_{0} V_{1}=\frac{g_{1}^{\prime}}{f_{1}^{\prime}}$, which determines optimal effort $x_{1}^{\star}$ and the benefit and cost of effort, $f_{1}\left(x_{1}^{\star}\right)$ and $g_{1}\left(x_{1}^{\star}\right)$.

Define the strike value $\bar{V}_{1}$ such that $N P V_{1}^{M}\left(\bar{V}_{1}\right)=0$. The entrepreneur exercises her option to invest at date 1 when $V_{1}>\bar{V}_{1}$ and $N P V_{1}^{M}>0$. This strike value is similar to the strike price of a traded option, except that the strike value has to cover the cost of the entrepreneur's effort $g_{1}\left(x_{1}^{\star}\right)$ as well as the investment $I_{1}$.

At date 0 , the entrepreneur anticipates her choice of effort and continuation decision at date 1 . She determines the effort level $x_{0}$ that maximizes $N P V_{0}$, the difference between the expected NPV at date 1 and the immediate investment $I_{0}$ and cost of effort $x_{0}$.

$$
N P V_{0}^{M}=\max \left[0, \max _{x_{0}}\left(E_{0}\left(N P V_{1}^{M}\left(x_{0}\right)\right)-g_{0}\left(x_{0}\right)-I_{0}\right)\right]
$$

$E_{0}\left(N P V_{1}^{M}\left(x_{0}\right)\right)$ depends on $x_{0}$ in two ways. First, increasing effort at date 0 increases $f_{0}$, and thus increases the value of the startup when it is in the money at date 1 . Second, increasing effort at date 0 decreases the strike value $\bar{V}_{1}$ for investment at date 1 and makes it more likely that the startup will continue.

The tradeoff between effort cost and startup value is illustrated in Figure 2. The top payoff line is the date-1 NPV for a call option with no cost of effort. In this case the value would be $V_{1}$ and the strike price $I_{1}$. The lower payoff line shows the net NPV when the 
entrepreneur exerts less than the maximum effort at date $0\left(f_{0}<1\right) . N P V_{1}$ is close to linear in $V_{1}$, but the slope and the level of $N P V_{1}$ are reduced by the cost of effort. We have added a lognormal distribution to show the probability weights assigned to these NPVs. The two horizontal lines are the date-0 financial investment $I_{0}$ and the full cost $I_{0}+g_{0}$ of investment and effort.

We calculate $E_{0}\left(N P V_{1}\right)$ by integrating from $\bar{V}_{1}\left(x_{0}\right)$. Since $N P V_{1}^{M}\left(x_{0}, \bar{V}_{1}\left(x_{0}\right)\right)=0$, the entrepreneur's first-order condition reduces to

$$
E_{0}\left(N P V_{1}^{M}\left(x_{0}^{\star}\right)\right)^{\prime}=g_{0}^{\prime}\left(x_{0}^{\star}\right)
$$

From (4) we obtain

$$
E_{0}\left(N P V_{1}^{M}\left(x_{0}\right)\right)^{\prime}=f_{0}^{\prime}\left[\int_{\bar{V}_{1}\left(x_{0}\right)}^{\infty} \Pi(V) V d V-\frac{1}{1+\theta_{r}}\left(\theta_{r}^{-\frac{\theta_{r}}{1+\theta_{r}}}+\theta_{r}^{\frac{1}{1+\theta_{r}}}\right) f_{0}^{-\frac{\theta_{r}}{1+\theta_{r}}} \int_{\bar{V}_{1}\left(x_{0}\right)}^{\infty} \Pi(V) V^{\frac{1}{1+\theta_{r}}} d V\right]
$$

where $\Pi(V)$ is the lognormal density and $\theta_{r}=\theta_{f} / \theta_{g}$.

We solve for $x_{0}^{\star}$ analytically, using properties of the lognormal distribution. Then we evaluate $N P V_{0}^{M}\left(x_{0}^{\star}\right)=E_{0}\left(N P V_{1}^{M}\left(x_{0}^{\star}\right)\right)-g_{0}^{\star}-I_{0}$. When $N P V_{0}^{M}\left(x_{0}^{\star}\right)>0$, the entrepreneur invests and the firm is up and running.

Table 1 includes examples of first-best numerical results. Start with the first two lines of Panel A, which report Black-Scholes and first-best results when potential value is $V_{0}=$ $E_{0}\left(V_{2}\right)=150$ and required investments are $I_{0}, I_{1}=50,50$. The standard deviation is $\sigma=0.4$ per period. The effort parameters are $\theta_{f}=1.8$ and $\theta_{g}=0.6$, so the value added by effort is high relative to the cost. Thus the option to invest in the startup should be well in the money, even after the costs of effort are deducted.

If the costs of effort were zero, first-best NPV could be calculated from the Black-Scholes formula, with a date- 1 strike price of $\bar{V}=50$. But when the cost of effort is introduced, $\bar{V}$ increases and NPV declines. First-best NPV is 37.90, less than the Black-Scholes NPV by 12.13. The difference reflects the cost of effort and the increase in strike value to $\bar{V}=55.35 .^{12}$

Panel B repeats the example with higher standard deviation of $\sigma=0.8$. Panels $\mathrm{C}$ and D assume lower investment at date 0 and higher investment at date $1\left(I_{0}, I_{1}=10,90\right)$. NPV increases for higher standard deviations and when more investment can be deferred. The first-best initial effort decreases in these cases, though not dramatically. Panels $\mathrm{E}$ and $\mathrm{F}$ assume $\theta_{f}=0.6$, so that effort is less effective, and also back-loaded investment (again, $I_{0}$, $\left.I_{1}=10,90\right) .{ }^{13}$ First-best effort actually increases, compared to panels $\mathrm{C}$ and $\mathrm{D}$, but NPV declines dramatically.

\footnotetext{
${ }^{12}$ The effort parameters in panel A of Table 1 are $\theta_{f}=1.8$ and $\theta_{g}=0.6$. Date 0 effort is $x_{0}=2.4$, so $f_{0}=0.99$ and $g_{0}=4.59$. Of course the date 0 effort is sunk by date 1 . From $(4), f_{1}^{*}=0.978$ and $g_{1}^{*}=3.58$. The breakeven value level $\bar{V}=55.35$ is determined by $0.99 \times 0.978 \times 55.35-3.58=I_{1}=50$.

${ }^{13}$ We do not include panels for equal investment $\left(I_{0}, I_{1}=50,50\right)$ and $\theta_{f}=0.6$, because NPVs are negative in all cases where outside venture-capital financing is required. A startup with these parameters could not be financed.
} 
Figure 3 plots first-best NPV for a wide range of standard deviations and effort parameters. Due to exponential function choice, only $\theta_{r}=\theta_{f} / \theta_{g}$, the ratio of the effort parameters, matters, so that ratio is used on the bottom-left axis. The ratio is $\theta_{r}=3$ in Panels A to $\mathrm{D}$ of Table 1 and $\theta_{r}=1.0$ in Panels $\mathrm{E}$ and $\mathrm{F}$. In Figure 3, $\theta_{r}$ is varied from 1/11 to 11. The startup becomes worthwhile, with first-best $N P V \geq 0$, for $\theta_{r}$ slightly below 1.0. NPV increases rapidly for higher values of $\theta_{r}$, then flattens out. NPV also increases with standard deviation, especially when most investment can be deferred to date 1 .

\section{Monopoly financing and staged investment}

Now we explore the monopoly case in which the entrepreneur approaches the venture capitalist for financing and the initial venture capitalist can dictate terms of financing at both date 0 and date 1 , subject to the entrepreneur's participation constraints. The venture capitalist will not exploit all his bargaining power, however, because of the feedback to the entrepreneur's effort. In some cases, the venture capitalist is better off if he gives up bargaining power and gives the entrepreneur all the financing upfront. We do not argue that the monopoly case is realistic, but it is a useful benchmark, and we believe that venture capitalists do have bargaining power, especially in early-stage financing, and receive at least some (quasi) rents.

By "terms of financing" we mean the fraction of common shares held by the entrepreneur and venture capitalist at dates 0 and 1 . The entrepreneur's fractional share at dates 1 and 2 is $\alpha_{1}^{M}$, the complement of $\alpha_{1}^{C}$. The entrepreneur's share at date 0 is irrelevant in the monopoly case, because a monopolist venture capitalist can force the terms of financing at date 1 and is free to dilute shares awarded earlier. We do assume that the entrepreneur has clear property rights to her shares at date 2 and that these shares cannot be taken away or diluted between dates 1 and 2 . The division of the final payoff $P$ is enforceable once date- 1 financing is completed.

\subsection{Effort and investment at date 1.}

Both the entrepreneur and the venture capitalist now have the option to participate at date 1. There are two derivative claims on one underlying asset. Both must be exercised in order for the project to proceed.

At date 1 the entrepreneur decides whether to exercise her option to continue, based on her strike price, the cost of optimal effort $g_{1}\left(x_{1}^{\star}\right)$. But first the venture capitalist sets $\alpha_{1}^{C}$ and $\alpha_{1}^{M}=1-\alpha_{1}^{C}$ and decides whether to put up the financial investment $I_{1}$. We can focus on the venture capitalist's decision if we incorporate the entrepreneur's response into the venture capitalist's optimization problem.

The equation for the entrepreneur's NPV is similar to Eq. (4), except that the secondperiod investment $I_{1}$ drops out and firm value is multiplied by the entrepreneur's share $\alpha_{1}^{M}$.

$$
N P V_{1}^{M}\left(\alpha_{1}^{C}\right)=\max \left[0, \max _{x_{1}}\left(\alpha_{1}^{M} f_{0} f_{1}\left(x_{1}\right) V_{1}-g_{1}\left(x_{1}\right)\right)\right]
$$


The maximum share the venture capitalist can take is obtained by setting $N P V_{1}^{M}\left(\alpha_{1}^{C}\right)=0$. This defines $\alpha_{1}^{C}(\max )$ and $\alpha_{1}^{M}(\min )$. When $\alpha_{1}^{M}(\min ) \geq \alpha_{1}^{M}$, the entrepreneur will not participate. ${ }^{14}$ The venture capitalist chooses $\alpha_{1}^{C \star}$ to maximize his date-1 NPV, subject to his and the entrepreneur's participation constraints.

$$
N P V_{1}^{C}=\max \left[0, \max _{\alpha_{1}^{C} \in\left(0, \alpha_{1}^{C}(\max )\right]}\left(\alpha_{1}^{C} f_{0} f_{1}\left(x_{1}^{\star}\right) V_{1}-I_{1}\right)\right]
$$

If the entrepreneur's participation constraint is binding, the venture capitalist assigns $\alpha_{1}^{C}(\max )$. Otherwise, he assigns an interior value. But in most of our experiments, $\bar{V}_{1}^{C}$, the venture capitalist's strike value for the monopoly case, falls in the region $\alpha_{1}^{C} \in\left[0, \alpha_{1}^{C}(\max )\right]$ where the entrepreneur's NPV is positive. In these cases the venture capitalist is better off by taking a share $\alpha_{1}^{C}<\alpha_{1}^{C}(\max )$ in order to give the entrepreneur stronger incentives. Nevertheless, those incentives are weaker than first-best, because $\alpha_{1}^{M \star}\left(x_{0}\right)<1$, which decreases the expected payoff by reducing $x_{1}^{\star}$.

Figure 4 plots values of $\alpha_{1}^{C}$ as a function of $V_{1}$ when $I_{0}=I_{1}=50, \sigma=0.4, \theta_{f}=1.8$, and $\theta_{g}=0.6$, the same parameters used in Panel A of Table 1. The optimal share $\alpha_{1}^{C \star}$ is less than the maximum share $\alpha_{1}^{C}(\max )=1-\alpha_{1}^{M}(\min )$ for all $V_{1} \geq \bar{V}^{C}$, the venture capitalist's strike value at date 1 . Thus the maximum share that the venture capitalist could extract is irrelevant. But notice that the venture capitalist's optimum share increases as the project becomes more valuable, with a corresponding decline in the entrepreneur's share. This implication of the monopoly case is contrary to the evidence in Kaplan and Stromberg (2003), who find that entrepreneurs gain an increasing fraction of payoffs as and if the firm succeeds. This suggests that in practice later-stage venture-capital financing is not provided on monopolistic terms.

Assuming the $\alpha_{1}^{C}(\max )$ constraint does not bind, we compute $\bar{V}_{1}^{C}$ by looking for the pair $\left.\bar{V}_{1}^{C}, \alpha_{1}^{C \star} \bar{V}_{1}^{C}\right)$ that sets $N P V_{1}^{C}$ equal to zero. Investment occurs if $V_{1}>\bar{V}_{1}^{C}$.

\subsection{Effort and exercise at date 0 .}

In the first-best case, the entrepreneur anticipates $x_{1}^{\star}$ and $I_{1}$ in her choice of $x_{0}$. In the monopoly case, the entrepreneur also anticipates the venture capitalist's decisions at date 1. She then evaluates whether $N P V_{0}^{C}\left(x_{0}^{\star}\right) \geq 0$. As in the first-best case, higher effort at $t=0$ lowers the threshold for investment at $t=1$ (makes it more likely that both the entrepreneur's and venture capitalist's options are in the money) and increases the value of the project when the option is in the money.

The entrepreneur's date 0 value is

$$
N P V_{0}^{M}=\max \left[0, \max _{x_{0}}\left(E_{0}\left(N P V_{1}^{M}\left(x_{0}\right)\right)-g_{0}\left(x_{0}\right)\right)\right]
$$

with the first-order condition

$$
E_{0}\left(N P V_{1}^{M}\left(x_{0}^{\star}\right)\right)^{\prime}=\Pi\left(\bar{V}_{1}\right) N P V_{1}^{M}\left(f_{0}^{\star}, \bar{V}_{1}\right) \bar{V}_{1}^{\prime}+g_{0}^{\prime}\left(x_{0}^{\star}\right)
$$

\footnotetext{
${ }^{14}$ When $f_{0}$ is small or $V_{1}$ is low, $\alpha_{1}^{M}(\min )$ may be greater than 1 , so that continuation is impossible even if the entrepreneur is given $100 \%$ ownership.
} 
Here there are no closed-form expressions. We solve the first-order condition and determine $x_{0}^{*}$ numerically. Given $x_{0}^{*}$, and assuming that the entrepreneur wants to go ahead $\left(N P V_{0}^{M}\left(x_{0}^{*}\right)>0\right)$, the venture capitalist invests if:

$$
N P V_{0}^{C}=\max \left[0, E_{0}\left(N P V_{1}^{C}\left(x_{0}^{\star}\right)\right)-I_{0}\right]>0
$$

Thus two options must be exercised at date 0 in order to launch the startup. The entrepreneur picks $x_{0}^{*}$ to maximize the value of her option to continue at date 1 , and then determines whether this value exceeds her current strike price, the immediate cost of effort $g_{0}^{*}$. The venture capitalist values his option to invest $I_{1}$ at date 1 , taking the entrepreneur's immediate and future effort into account, and then decides whether to invest $I_{0}$.

Monopoly financing can be extremely inefficient. The venture capitalist's ability to claim a large ownership fraction at date 1 reduces the entrepreneur's effort at date 0 as well as date 1 , reducing value and increasing the venture capitalist's breakeven point $\bar{V}_{1}^{C}$. For example, compare the monopoly and first-best results in Panel A of Table 1. The entrepreneur's initial effort falls by about 50 percent from the first-best level and the date- 1 strike value $\bar{V}_{1}^{C}$ increases by almost 30 percent. The entrepreneur's NPV drops by more than 90 percent. Overall NPV drops by more than half. Similar value losses occur in panels B to F. In Panel E, a startup with first-best NPV of 10.98 cannot be financed in the monopoly case. NPV would be negative for both the entrepreneur and the initial venture capitalist.

\subsection{Monopoly financing without staged investment}

The incentive problems of the monopoly case can sometimes overwhelm the option-like advantages of staged financing. All may be better off if the entire investment $I_{0}+I_{1}$ is given to the entrepreneur upfront and she is granted full control thereafter.

In the monopoly, no-staging case, the entrepreneur and venture capitalist bargain only once at date 0 to determine their ownership shares $\alpha^{M}$ and $\alpha^{C}$, which are then fixed for dates 1 and 2. The entrepreneur calculates her NPV at date 1 just as in the monopoly case with staging, but her share of the firm $\alpha_{1}^{M}$ is predetermined. Also, she ignores the financial investment $I_{1}$ and continues at date 1 so long as her NPV exceeds her cost of effort, $g_{1}\left(x_{1}^{\star}\right) .{ }^{15}$ The venture capitalist retains monopoly power over financing at date 0 , but loses all his bargaining power at date 1 . He sets $\alpha^{C}$ to maximize his NPV at date 0 , taking into account the effects on the entrepreneur's effort at dates 0 and 1 . His maximization problem is identical in appearance to Eq. (10) but the values of $x_{0}^{*}, x_{1}^{*}$ and $\alpha_{1}^{C}=\alpha_{0}^{C}$ are different. The entrepreneur's date-0 maximization problem closely resembles Eq. (8) except for the choices of $x_{1}^{*}$ and $\alpha_{1}^{C}=\alpha_{0}^{C}$. If both parties' participation constraints are met at date $0\left(N P V_{0}^{C} \geq 0\right.$ and $N P V_{0}^{M} \geq 0$ ), the startup is launched.

The value loss from the holdup problem in the monopoly, staged financing case can be so severe that it can actually exceed the cost of inefficient continuation in the no-staging case. For example, note the improvement in the no-staging case in Panel A of Table 1. The

\footnotetext{
${ }^{15}$ We do assume that the entrepreneur cannot launch the firm at date 0 and then run off with the date- 1 investment $I_{1}$. Venture-capital investors typically hold convertible preferred shares and have priority in liquidation.
} 
NPV to the entrepreneur more than doubles, compared to the monopoly case with staged investment, and overall NPV increases from 16.47 to 26.89 .

Figures 5 and 6 compare the monopoly NPVs with and without staging. Figure 5 assumes equal investment in both periods $\left(I_{0}, I_{1}=50,50\right)$. Here NPV is higher without staging, except at extremely high standard deviations. Figure 6 assumes back-loaded investment $\left(I_{0}\right.$, $\left.I_{1}=10,90\right)$, which adds to option value and the value of staging. In Figure 6 , a monopolist venture capitalist would give up staging and provide $100 \%$ upfront financing only at relatively low standard deviations.

\section{Syndication}

The value losses in the monopoly case would be reduced if the entrepreneur could promise higher effort at date 1 , or if the venture capitalist could promise to take a lower ownership fraction $\alpha_{1}^{C}$. Neither promise is credible, however, since effort and potential value are noncontractible. But suppose that the venture capitalist can commit (explicitly or implicitly) to bring in a syndicate of new investors to join him in the date- 1 financing. Suppose further that the incumbent venture capitalist does not collude with syndicate members and allows them to dictate the terms of financing. We will show that these commitments are in the initial venture capitalist's interest. Syndication alleviates the holdup problem and generates extra effort and value.

Syndication of later stage financing is common in practice. The initial venture capitalist approaches a group of other venture-capital investors that he has worked with in the past, or hopes to work with in the future, and offers participation in the financing. We interpret syndication as a mechanism that introduces competition into date- 1 financing and restrains the initial venture capitalist's temptation to hold up the entrepreneur. We do not know what NPV syndicates obtain in practice, but it is natural to explore NPV $=0$ as a limiting case. (If the syndicate gets positive NPV, but still less than a monopolist venture capitalist could extract, there are still value gains relative to the monopoly case.) We start with the full-information case, where the investors who compete to join the syndicate have the same information as the incumbent venture capitalist. ${ }^{16}$

The results for syndicate financing differ from the monopoly case in at least two ways. First, the terms of financing shift in the entrepreneur's favor. The new syndicate investors are forward-looking. They do not care about the value of the existing shares held by the incumbent venture capitalist and have no incentive to hold up the entrepreneur. The incumbent has no control over the terms of financing at date 1, so his ultimate ownership and payoff are determined by his initial share $\alpha_{0}^{C}$ and the performance of the startup. The syndicate accepts $N P V^{S}=0$ and does not trade off extra NPV against reduced effort from the entrepreneur. Thus the syndicate's ownership share $\alpha_{1}^{S}$ will generate lower $N P V^{S}$ than the NPV-maximizing share $\alpha_{1}^{C *}$ that a monopolist incumbent would set. The entrepreneur suffers less dilution, exerts more effort, and total value increases. This outcome benefits the initial venture capitalist at date 0 . By delegating the terms of date-1 financing, he solves the

\footnotetext{
${ }^{16}$ We doubt that potential syndicate investors really have full information. If they did, then the entrepreneur could negotiate with these investors directly and possibly hold up the incumbent venture capitalist. This scenario seems implausible and we do not explore it in this paper.
} 
incomplete contracting problem that causes the holdup problem in the monopoly case with staged financing.

Second, under zero-NPV date-1 financing, the initial venture capitalist effectively owns a call option with a zero exercise price and will always want the investment to proceed at date 1 whether or not the project can generate enough value to cover the syndicate's investment. With full information, it does not matter whether the initial venture capitalist participates in the syndicate, because the syndicate's investment is zero-NPV. Of course the initial venture capitalist's participation matters if the syndication terms are not fully competitive. The higher the NPV for the syndicate, the closer is the syndicate case to the monopoly case.

\subsection{Effort and investment at date 1}

For a given share $\alpha_{1}^{M}$, the entrepreneur's NPV and maximization problem at date 1 are the same as in the monopoly case. We obtain $x_{1}^{\star}, f_{1}^{\star}, g_{1}^{\star}$, and $N P V_{1}^{M}\left(\alpha_{1}^{S}\right)$ exactly as in Eq. (6), but with $\alpha_{1}^{M}=\alpha_{0}^{M}\left(1-\alpha_{1}^{S}\right)$. The share given to the outside syndicate, $\alpha_{1}^{S}$, is determined by $N P V_{1}^{S}=0$, that is, by $I_{1}=\alpha_{1}^{S} f_{0} f_{1}\left(x_{1}\right) V_{1}$. Investment at date 1 occurs for $V_{1}>\bar{V}_{1}^{S}$. We solve for $\bar{V}_{1}^{S}$ by finding the value of $\alpha_{1}^{S}$ that maximizes $N P V_{1}$, subject to the constraint that $N P V^{S}=0$ for the syndicate. The solution is generally in the region where $N P V_{1}^{M}\left(\alpha_{1}^{S}\right)>0$ at $\bar{V}_{1}$ and $\alpha_{1}^{M}<\alpha_{1}^{M}(\min )$.

Figure 7 plots ownership shares against value at date 1 for the syndicate case when $I_{0}, I_{1}=50,50, \sigma=0.4, \theta_{f}=1.8$ and $\theta_{g}=0.6$, the same parameters used in Panel A of Table 1. The top two lines show the syndicate's maximum and optimal shares if the new investors were given free rein to maximize their NPV. The maximum share is irrelevant, as in Figure 4. The syndicate's actual share equals its optimal share at the strike value $\bar{V}_{1}^{S}$ and then declines as $V_{1}$ increases. The shares held by the entrepreneur and incumbent venture capitalist therefore increase as performance improves, consistent with the evidence in Kaplan and Stromberg (2003) and contrary to the pattern in the monopoly case, as plotted in Figure 4.

One might expect the better financing terms from the syndicate to decrease the strike value $\bar{V}_{1}$ from the monopoly case. But $\bar{V}_{1}$ is actually higher in the syndicate case - for example, $\bar{V}_{1}$ is 84.9 in Figure 7 and 70.8 in Figure 4 . This increase can be traced to the initial venture capitalist's fixed original ownership share in the syndicate-financing case. When the original venture capitalist provides both rounds of financing, he picks the share at date 1 that is best for him at date 1. He may reduce his share to strengthen the entrepreneur's incentives. Unlike the monopolist, the syndicate cannot reset the venture capitalist's original share $\alpha_{0}^{C}$ and is there therefore faced with a free-riding incumbent. The syndicate has a smaller value pie to carve up, and a higher threshold for investment.

Thus the commitment to syndicate later-stage financing has two countervailing effects. The syndicate may require a higher threshold for investment, so that marginal projects will be rejected more often. On the other hand, syndication provides better incentives for the entrepreneur, so that low values of $f_{0} V_{1}$ are less likely. Our numerical analysis will show that the second effect outweighs the first and that shifting from monopoly to syndication always adds value. 


\subsection{Renegotiation at date 1}

Of course a low realization of $V_{1}$ could trigger a renegotiation between the incumbent and the entrepreneur to reset the incumbent's initial share $\alpha_{0}^{C}$ before syndicate financing is sought. The incumbent can transfer ownership to the entrepreneur, retaining $\alpha^{C}(R)<\alpha_{0}^{C *}$, where $\alpha^{C}(R)$ denotes the incumbent's renegotiated equity stake. The incumbent may be better off accepting a reduced ownership share to improve the chance of success for low values of $V_{1}$ or to increase continuation for $V_{1}<\bar{V}_{1}^{S}$. By accepting a lower ownership share, the incumbent improves effort incentives for the entrepreneur to the point where enough extra value is added to support syndicate financing at NPV $=0$. Of course the incumbent will give up as little as possible. In the worst renegotiation case, where $V_{1}$ approaches a lower bound, the value of the incumbent's shares approaches zero, just as in the monopoly case.

Renegotiation requires dilution of the incumbent venture capitalist's ownership share. Dilution could happen in several ways. For example, the incumbent could provide bridge financing on terms favorable to the entrepreneur. Dilution could also occur in a "down round" - a round of financing where new investors buy in at a price per share lower than in previous rounds. But our model says that a down round should dilute the entrepreneur less than the incumbent venture capitalist. The entrepreneur could be given additional shares or options, for example.

While renegotiation adds value ex post by improving effort and preserving access to financing, the flexibility to reset shares at date 1 could introduce new problems. Suppose the initial venture capitalist sets $\alpha_{0}^{C}$ at a very high level, knowing that he can renegotiate down to the monopoly level at date 1 , even when the realized value $V_{1}$ exceeds the syndicate strike value $\bar{V}_{1}^{S} \cdot{ }^{17}$ The entrepreneur would then cut back effort at dates 0 and 1 and reduce the value of the firm. This strategy amounts to a return to monopoly financing. It would reduce date- 0 value to the venture capitalist as well as the entrepreneur.

Thus two conditions must hold in order for syndicate financing to work as we have described it. First, the initial venture capitalist has to commit at date 0 to syndicate at date 1 . In practice this is not an explicit, formal commitment, but syndication is standard operating procedure. As part of the commitment, the initial venture capitalist has to limit his initial ownership share $\alpha_{0}^{C}$ to its level in the syndicate case, so that he cannot start with a higher value and bargain down to the monopoly share $\alpha_{1}^{C *}$ at date 1 . The commitment is in the venture capitalist's interest, because it increases his ex ante value relative to the monopoly case. Second, the terms of financing in later rounds should be reasonably competitive. In practice they may not be perfectly competitive, but we believe the terms are materially better for the entrepreneur than the monopoly terms would be.

It turns out that opportunities for renegotiation are rare in our numerical experiments for the syndicate case. Therefore, incorporating the benefits of renegotiation would add relatively little to NPV at date 0 . For example, including renegotiation gains would increase the NPVs reported in Table 1 by about $2 \%$ of the required total investment of $I_{0}+I_{1}=100 .{ }^{18}$

\footnotetext{
${ }^{17}$ The entrepreneur could retain the upside if she could bypass the incumbent venture capitalist and go directly to the syndicate for financing. In practice the incumbent could block this end run by refusing to participate in the syndicate. The syndicate would assume that the incumbent has inside information, and would interpret the refusal to participate as bad news sufficient to deter their investment.

${ }^{18}$ We approximate renegotiation gains (holding $\alpha_{0}^{C *}$ and $x_{0}$ constant) by solving for (1) the value realization
} 


\subsection{Effort and exercise at date 0}

At date 0 , the venture capitalist sets $\alpha_{0}^{C}$ and the entrepreneur decides how much effort to exert. Given $\alpha_{0}^{C}$, the entrepreneur chooses $x_{0}$ to maximize:

$$
N P V_{0}^{M}\left(\alpha_{0}^{C}\right)=\max \left[0, \max _{x_{0}}\left(E_{0}\left(N P V_{1}^{M}\left(x_{0}\left(\alpha_{0}^{C}\right), \alpha_{0}^{C}\right)-g_{0}\left(x_{0}\left(\alpha_{0}^{C}\right)\right)\right)\right]\right.
$$

The entrepreneur anticipates the syndicate's share $\alpha_{1}^{S}$ as a function of date- 1 value $V_{1}$. For a given $\alpha_{0}^{C}$, date-1 syndicate financing will result in less dilution of her share than in the monopoly case, so she provides higher effort at $t=0$ as well as at $t=1$. We cannot express NPV or effort in closed form, so we compute them numerically.

The venture capitalist anticipates the entrepreneur's reaction when he sets $\alpha_{0}^{C}$. He must restrict his search to $\alpha_{0}^{C} \in\left(0, \alpha_{0}^{C}(\max )\right]$, where $\alpha_{0}^{C}(\max )$ is determined by

$$
E_{0}\left(N P V_{1}^{M}\left(x_{0}^{\star}\left(\alpha_{0}^{C}(\max )\right), \alpha_{0}^{C}(\max )\right)-g_{0}\left(x_{0}^{\star}\left(\alpha_{0}^{C}(\max )\right)\right)\right)=0
$$

This constraint rarely binds, since at the margin there is almost always value added by leaving positive value to the entrepreneur. Thus $\alpha_{0}^{C *}$ is determined by

$$
\alpha_{0}^{C \star}=\arg \max _{\alpha_{0}^{C} \in\left(0, \alpha_{0}^{C}(\max )\right]}\left(E_{0}\left(N P V_{1}^{C}\left(x_{0}^{\star}\left(\alpha_{0}^{C}\right), \alpha_{0}^{C}\right)\right)-I_{0}\right)
$$

If $N P V_{0}^{C} \geq 0$, investment proceeds.

Typical results for syndicate financing are shown in Table 1. Effort and value increase across the board, despite increases in the strike value $\bar{V}_{1}^{S}$ from the monopoly case. We find that syndicate financing dominates monopoly financing with or without staged financing. Syndicate financing is better ex ante for the initial venture capitalist and also increases overall NPV. This is true for all parameter values, including values outside the range reported in Table 1. Yet there are still value losses relative to the first best.

\subsection{The fully competitive case}

Of course first best is never attainable when the entrepreneur has to seek outside financing. Table 1 shows an alternative benchmark, the fully competitive case, in which all venture capital investors, including the initial investor at date 1 , receive $N P V=0$. Fully competitive financing gives an upper bound on the overall NPV when the entrepreneur has no money and has to share her marginal value added with outside investors. Solution procedures for the fully competitive case are identical to the syndication case, except that $\alpha_{0}^{C}$ is set so that $N P V_{0}^{C}=0$.

Figure 8 shows date- 1 ownership shares for the fully competitive case in the same format as the syndication case in Figure 7. Two things stand out. First, the entrepreneur's share

at which the venture capitalist will start to reduce his share; (2) the new strike value and (3) the integral of NPV changes over this range. Only a small portion of the renegotiation gains come from more efficient continuation decisions $\left(\bar{V}_{1}^{S}(R)<V_{1}<\bar{V}_{1}^{S}\right)$. Most of the gains can be attributed to better effort incentives (higher $x_{1}$ ) in the region where the project continues regardless $\left(V_{1}>\bar{V}_{1}^{S}\right)$. These gains further increase the value advantages of syndicate financing over monopoly financing. 
is higher and the initial venture capitalist's lower than in Figure 7, because competitive financing at date 0 gives relatively more shares to the entrepreneur. Both shares of course increase with the realized value $V_{1}$. Second, the strike value $\bar{V}_{1}$ is lower in the competitive case, primarily because the entrepreneur's initial effort is higher. Note also that the fully competitive NPVs, which go entirely to the entrepreneur, are less than in the first-best case, because the entrepreneur's effort is lower. There is always some value loss when the entrepreneur has to share the marginal value added by her effort with outside investors.

\subsection{Syndication with asymmetric information}

So far we have assumed that the incoming syndicate investors and the incumbent venture capitalist are equally informed. Now we consider asymmetric information between the incumbent and new investors.

Both the incumbent and entrepreneur want the syndicate to perceive a high value $V_{1}$. The more optimistic the syndicate, the higher the ownership shares retained by the incumbent and entrepreneur. Reducing the syndicate's share also increases the entrepreneur's effort. Therefore, mere announcements of "great progress" or "high value" coming from the entrepreneur or incumbent are not credible.

Credibility may come from the incumbent's fractional participation in date- 1 financing. Suppose the incumbent invests $\beta I_{1}$ and the outside syndicate the rest. What participation fraction $\beta$ is consistent with truthful revelation of $V_{1}$ ? If we could hold the entrepreneur's effort constant, we could rely on Admati and Pfleiderer's (1994) proof that $\beta$ should be fixed at the incumbent investor's ownership share at date 0 , that is, at $\alpha_{0}^{C}$. This fixed-fraction rule would remove any incentive for the incumbent to over-report $V_{1}$. (The more he overreports, the more he has to overpay for his new shares. When $\beta=\alpha_{0}^{C}$, the amount overpaid cancels out any gain in the value of his existing shares. ${ }^{19}$ The fixed-fraction rule would also insure optimal investment, since the incumbent's share of date-1 investment exactly equals his share of the final payoff $V_{2}$. Admati and Pfleiderer also show that no other financing rule or procedure works in their setting.

Fixed-fraction financing does not induce truthful information revelation in our model, although a modified fixed-fraction financing works in some cases. The problem is the effect of the terms of date-1 financing on the entrepreneur's effort. Suppose the incumbent investor takes a fraction $\beta=\alpha_{0}^{C}$ of date- 1 financing and then reports a value $\hat{V}_{1}$ that is higher than the true value $V_{1}$. If the report is credible, the new shares are over-priced. The incumbent does not gain or lose from the mispricing, because $\beta=\alpha_{0}^{C}$, but the entrepreneur gains on his old shares at the syndicate's expense. Since the entrepreneur's ownership share is higher than it would be under a truthful report, she exerts more effort, firm value increases, and both the entrepreneur and incumbent are better off. Therefore the incumbent will over-report.

A modified fixed-fraction rule can work, however, provided that $\beta$ is set above $\alpha_{0}^{C}$ and effort is not too sensitive to changes in the entrepreneur's NPV at date 1 . The required difference between $\beta$ and $\alpha_{0}^{C}$ depends on the responsiveness of the entrepreneur's effort to

\footnotetext{
${ }^{19}$ The fixed-fraction rule would also remove any incentive to underreport. The more the incumbent underreports, the more he gains on the new shares. But the amount of profit made on the new shares is exactly offset by losses incurred on existing shares.
} 
her ownership share. In many cases, a constant $\beta$ set a few percentage points above $\alpha_{0}^{C}$ removes the incentive to overreport over a wide range of $V_{1}$ realizations. But this rule may break down as a general revelation mechanism in at least three ways.

First, when $V_{1}$ is very low but exceeds $\bar{V}_{1}$, we find situations where the required $\beta$ exceeds 1. This would make sense only if the new syndicate investors could short the company, so we must constrain $\beta<1$. This outcome is common in our numerical results, because the incumbent's initial share $\alpha_{0}^{C}$ is frequently above $85 \%-90 \%$, and in some of these cases the entrepreneur's effort is very sensitive to the value of her stake in the firm. There is not much room for $\beta$ to increase between these starting points and a maximum level strictly less than 1 . When $\beta$ hits the maximum, the modified fixed fraction rule fails to induce truthful revelation. ${ }^{20}$

Second, the modified fixed fraction rule also fails when $V_{1}$ falls just below $\bar{V}_{1}$. In this case the incumbent's incentive to over-report becomes very strong, and only extremely high $\beta_{\mathrm{s}}$ can discipline the incumbent to tell the truth. This problem flows from the discontinuity of the entrepreneur's effort at the strike value $\bar{V}_{1}$. Here the limit of $\beta$ as $V_{1}$ approaches $\bar{V}_{1}$ from below is infinity and no fixed-fraction rule works. This problem can be solved, however, if the incumbent and the entrepreneur renegotiate their ownership shares when $V_{1}$ falls between the monopoly and syndicate strike values $\bar{V}_{1}^{C}$ and $\bar{V}_{1}^{S}$. If the incumbent venture capitalist renegotiates, the lower strike value removes the discontinuity of effort. As the incumbent's share declines, it is easier to find a $\beta<1$ that works. The required $\beta$ approaches 0 as $V_{1}$ approaches $\bar{V}_{1}^{C}$ and the incumbent's share approaches zero.

The third problem arises at high levels of $V_{1}$. Setting $\beta>\alpha_{0}^{C}$ gives the incumbent venture capitalist an incentive to under-report $V_{1}$. The incumbent would gain more from underpricing the new shares and buying them cheaply than he would lose from dilution of his existing stake. Revelation works only if this incentive is offset by the impact on the entrepreneur's effort. But as $V_{1}$ and $\hat{V}_{1}$ increase, effort becomes higher and less sensitive to the terms of financing. As effort tops out, the incentive to under-report takes over. This could be prevented locally by allowing $\beta$ to decrease with $\hat{V}_{1}$, returning to $\beta=\alpha_{0}^{C}$ at very high values. But then the almost-fixed fraction rule fails globally to induce truthful information revelation, because at lower $V_{1}$ realizations he wants to over-report to these higher levels at which $\beta=\alpha_{0}^{C}$.

One possible solution, not fully explored here, is to introduce more complex contracts that allow signalling along two dimensions. For example, the incentive for the incumbent venture capitalist to under-report at high levels of $V_{1}$ could be offset by an incentive contract that grants the entrepreneur extra shares if the incumbent reports very high project value. With this additional provision in place, it should be possible to allow $\beta$ to decrease with $\hat{V}_{1}$, reaching $\beta=\alpha_{0}^{C}$ at high values of $V_{1}$. This could be one justification for contingent share awards to the entrepreneurs, as observed in Kaplan and Stromberg (2003). Alternatively, the entrepreneur could be granted a series of stock options with increasing exercise prices, so that the entrepreneur's final ownership share increases at high values of $V_{2}$.

\footnotetext{
${ }^{20}$ This failure is less frequent if the entrepreneur has some personal wealth and can co-invest with the venture capitalist at date 0 . The coinvestment reduces the venture capitalist's ownership share and provides more room for $\beta$ to increase to a maximum level strictly less than 1.
} 
When the modified fixed fraction rule fails, the syndicate investors face the asymmetric information problem analyzed by Myers and Majluf (1984). In the special case of their model that is closest to our problem here, the firm has no assets in place (no value in liquidation), so it goes ahead with financing on terms fixed by the new investors' knowledge of the average value of $V_{1}$. Syndicate investors would have to infer the average $V_{1}$ from conditions at date 0 , the entrepreneur's effort functions and the entrepreneur's and incumbent's decision rules, given the anticipated terms of date-1 financing. But the investors do not know the true value $V_{1}$, so their new financing is overpriced when $V_{1}$ is low and underpriced when $V_{1}$ is high. This leads to more effort when $V_{1}$ is low and less when it is high, compared to the full-revelation case. But again there are problems. For example, if $V_{1}$ is high, the incumbent will be better off cancelling syndicate financing and providing the date-1 money directly. But if this is allowed, then the incumbent will have an incentive to claim a high value $V_{1}$ in order to reclaim monopoly power over the terms of financing. In addition, if the syndicate investors know less than the incumbent and the incumbent is free to finance the investment from his own pocket, then the incumbent will only raise syndicate financing if the syndicate is paying too much. Therefore a rational syndicate will not invest. ${ }^{21}$

Even if the revelation mechanism fails, there may be other ways to convey $V_{1}$. The value of the incumbent investor's reputation could generate truthful reports in a repeated game setting, for example. The syndicate usually includes other venture capitalists that the incumbent has worked with in the past and expects to work with in the future.

\section{$5 \quad$ Summary of Numerical Results}

Table 1 illustrates our main results. It shows surprisingly large value losses in most cases, relative to first-best. (For now ignore the debt-financing entries.) Value losses are greatest in the monopoly case where the initial venture capitalist provides all financing and dictates the terms of financing at date 1 as well as date 0 . This does not imply that the venture capitalist extracts all value, leaving the entrepreneur with zero NPV. The venture capitalist wants to preserve the entrepreneur's incentives to some extent. Nevertheless, the financing terms that maximize value for the venture capitalist usually leave the entrepreneur with a small minority slice of a diminished pie.

The problem with staged financing is that a monopolistic venture capitalist cannot commit not to hold up the entrepreneur ex post. Thus NPV can be higher and the initial venture capitalist better off if staged financing is abandoned and all financing is committed at date 0 . Complete upfront financing is superior for all effort parameters (all values of $\theta_{r}=\theta_{f} / \theta_{g}$ ) when option value is relatively low, as it is for most of the range of standard deviations in Figure 5. Figure 6 shows that when the option value is high, staged financing is more efficient, despite the monopoly holdup problem.

Syndication of date-1 financing always makes both the entrepreneur and the initial venture capitalist better off as long as the syndicate's financing terms are reasonably competitive. This key result of our paper is evident in Table 1 and also holds generally. We believe that our syndicate case, in which the initial venture capitalist can set financing terms at date 0 but not date 1 , is a good match to actual venture capital contracting. Of course we

\footnotetext{
${ }^{21}$ This is a variation of Myers and Majluf's (1984) pecking-order proofs.
} 
observe syndication in practice, but that observation does not settle whether the terms of syndicate financing are competitive $(\mathrm{NPV}=0)$ or monopolistic. Our analysis indicates that syndication terms are reasonably competitive. With monopoly financing terms at date 1, we find that the entrepreneur's final ownership share is a decreasing function of firm value. With competitive terms, as in our syndication case, the entrepreneur's share is an increasing function of value, consistent with practice (Kaplan and Stromberg (2003)).

The syndicate case is still inefficient, because it gives the initial venture capitalist the bargaining power to set financing terms at date 0 . We believe that venture capitalists do have bargaining power and receive at least some (quasi) rents in early financing rounds. They have bargaining power because of experience and expertise, because of the fixed costs of setting up a venture capital partnership and because of the cost and delay that the entrepreneur would absorb in looking for another venture-capital investor. But there are obviously efficiency improvements if and as the terms of date- 0 financing become more competitive. The fully competitive case shows the limit where the initial venture capitalist has no special bargaining power and just receives NPV $=0$. Even the fully competitive case falls short of first best, however. The entrepreneur's effort falls whenever outside financing has to be raised, because the entrepreneur bears the full cost of effort, but has to share the marginal value added by effort with the outside investors.

Figure 9 summarizes value losses for the monopoly, no-staging, syndication and fully competitive cases over a wide range of the effort parameter $\theta_{r}$. Value loss is defined as the difference between NPV at date 0 and first-best NPV. The four panels correspond to panels A to $\mathrm{D}$ in Figure 1, except for the variation in $\theta_{r}$. Figure 10 repeats Figure 9 for a more profitable startup with $V_{0}=200$.

The value losses plotted in Figure 9 increase rapidly with $\theta_{r}$ when $\theta_{r}$ is below 1.0, but the losses are always less in the syndication case than in the monopoly cases. The losses in the syndicate case still appear economically significant, however. The only situations in which losses do not appear significant occur in the fully competitive case when $\theta_{r}$ is above 2.0. High values for $\theta_{r}$ mean that effort generates value at relatively little cost, so that the entrepreneur is willing to expend close to first-best effort in the fully competitive case, even though the marginal benefit of effort is shared with outside investors.

Value losses in the monopoly, no staging case increase as standard deviation is increased from $\sigma=0.4$ to 0.8 . This is as expected, since staged financing is more valuable as volatility increases. But value losses may also increase with standard deviation in the monopoly and syndication cases, at least for the region where $\theta_{r}$ is about 1.0 and higher. We found this surprising. Our original intuition was that increased uncertainty would enhance the optionality of investment and mitigate incentive problems. Instead it can make these problems worse, because more uncertainty can lead to lower initial effort. ${ }^{22}$ Compare the bottom-left and bottom-right panels in Figure 9, for example. The effects of volatility on effort and value can also be seen in panels $\mathrm{E}$ and $\mathrm{F}$ of Table 1 . In the syndicate case, the value loss in panel

\footnotetext{
${ }^{22}$ When overall NPV is near zero, the entrepreneur's effort $x_{0}$ increases rapidly with $\sigma$. The more uncertainty, the greater chance that the entrepreneur's call option will be in the money and the greater the marginal reward to effort. But as $\theta_{r}$ increases and NPV rises, effort eventually declines as $\sigma$ increases, because the marginal impact of effort is less. The difference can be traced to the slope of the cumulative lognormal, which is lower at the mean when $\sigma$ is high.
} 
$\mathrm{E}$, with $\sigma=0.4$, is $10.98-1.55=9.43$. In panel $\mathrm{F}$, with $\sigma=0.8$, value loss is $27.72-17.50$ $=10.22$. Initial effort falls from $x_{0}=3.05$ in panel $\mathrm{E}$ to $x_{0}=2.80$ in panel $\mathrm{F}$.

The value-loss patterns in Figure 9 are repeated in Figure 10, where $V_{0}=200$ rather than 150. Financing is feasible in Figure 10 at lower levels of the effort parameter $\theta_{r}$. Value losses are lower for the fully competitive case, but actually increase for the monopoly and syndication cases. This problem can be traced to the initial venture capitalist's bargaining

power at date 0 . Consider the monopoly case. Since the marginal product of effort is higher when $V_{0}=200$, the entrepreneur will put in more effort at date 1 . This allows the initial venture capitalist to tighten the screws and extract a greater ownership share, which in turn feeds back to lower effort by the entrepreneur at date 0 .

The effects of other parameters on our results are generally as expected. NPV increases when the ratio $\theta_{r}=\theta_{f} / \theta_{g}$ increases. The strike value $\bar{V}$ falls with $\theta_{r}$, increasing the probability that the date-1 option to invest is in the money, and when the option is in the money it is worth more. Overall NPV increases when $\sigma$ increases (generating more uncertainty in $V_{1}$ and $V_{2}$ ) and when a greater fraction of investment can be deferred to date 1 . These effects are natural for investments in real options.

\section{Debt financing}

So far we have considered only equity financing, following venture-capital practice. Is equity financing efficient for venture capitalists? We cannot answer this question without deriving optimal contracts, a task that we do not attempt in this paper. But it is interesting to consider the alternative of debt financing. We have interpreted syndicate financing as a device to secure the entrepreneur's effort by protecting her from ex-post holdup. Could a switch to debt financing achieve the same or better result? In traditional agency models, debt financing calls forth maximum effort, because the entrepreneur retains the maximum fraction of the value added at the margin by her effort. Perhaps we have oversimplified venture-capital practice to the extent that debt dominates equity as a financing contract.

In this section we show that debt is not superior to equity. When effort and investment are made in stages, debt financing can actually amplify the hold-up problem and reduce the entrepreneur's initial effort at date 0 . We will show that debt financing could increase efficiency in some cases, however.

Suppose that the startup firm issues debt rather than equity to venture-capital investors. The face value of the debt equals the required investment. Of course, this debt faces a high probability of default, so the promised payoff at date 2, including interest, is well above face value. (Safe debt is nearly impossible, given the high variance of most startups and most entrepreneurs' limited funds available for equity investment.) The promised debt payoff (face value plus interest) sets a strike value for $V_{2}$ below which the startup defaults and the investors receive all of the startup's payoff $P$. Above this point the investors' payoff is capped and the entrepreneur receives the residual. Thus debt financing converts the entrepreneur's stake to a call option, and our discussion of debt financing also applies if the entrepreneur receives no shares but only options. The implicit call options created by debt financing would probably be out of the money, however, because the promised payment to the venture 
capitalists would have to exceed total investment by enough to cover the risk of failure and default.

Now we revisit the monopoly case, holding all aspects of our model constant, except that at date 1 the venture capitalist and entrepreneur negotiate a promised debt payoff $K_{1}$ instead of ownership shares $\alpha_{1}^{C}$ and $\alpha_{1}^{M}$. (With debt, $\alpha_{1}^{M}=1$.) The entrepreneur's NPV at date 1 is her expected residual payout at date 2 , that is, $E_{0}\left[\max \left(0, f_{0} f_{1} V_{2}-K_{1}\right)\right]$. As before, the entrepreneur chooses effort to maximize $N P V_{1}^{M}$, and the venture capitalist chooses $K_{1}^{*}$ to maximize $N P V_{1}^{C}$. The startup continues if $N P V_{1}^{C}>I_{1}$. At date 0 , the entrepreneur anticipates $K_{1}^{*}$ and chooses initial effort accordingly. We solve numerically for the entrepreneur's effort, the promised payoff $K_{1}^{*}$ and the venture capitalist's and entrepreneur's NPVs. If both parties' participation constraints are met at date 0 , the venture is launched.

Table 1 shows examples comparing debt versus equity financing in the monopoly case. It is immediately clear that debt is no panacea. When monopoly debt financing is feasible, it can enhance effort and NPV. In Panels B and D of Table 1, for example, initial effort is higher and NPVs increase in the monopoly (debt) cases. The resulting NPVs in these cases approach the fully competitive outcome. But in Panels A, C and F startups that could be financed by a monopolist venture capitalist with equity cannot be financed with debt. This breakdown occurs because debt makes the holdup problem worse. At date 1, the venture capitalist is able to set the promised debt payoff so high that the entrepreneur is left with with a very small slice of value. The entrepreneur's effort at date 1 is increased, given $K_{1}^{*}$, because the entrepreneur holds an option and receives all value in excess of $K_{1}^{*}$. But the entrepreneur's date-1 NPV is very small, and her effort at date 0 is drastically reduced. It appears that linear equity contracts between the entrepreneur and venture capitalist mitigate the hold-up problem at date 1 and generate more efficient effort at date 0.

In the syndicate financing case, the venture capitalist negotiates an initial debt level $K_{0}^{C}$ at date 0 in exchange for initial funding. At date 1, if $V_{1}$ is large enough, new, pari passu debt with face value $K_{1}^{S}$ is issued to a syndicate of investors for zero expected return. The incumbent venture capitalist and syndicate share in debt payouts at date 2 according to their shares of debt ownership $\frac{K_{0}^{C}}{K_{0}^{C}+K_{1}^{S}}$ and $\frac{K_{1}^{S}}{K_{0}^{C}+K_{1}^{S}}$. The entrepreneur makes the same decisions as in the monopolistic case, but faces the combined debt level $K_{0}^{C}+K_{1}^{S}$. As before, the syndicate provides date-1 financing on competitive terms.

Introducing debt contracts in the syndication case increases the entrepreneur's initial effort, but also increases $\bar{V}$, the threshold for project continuation. Higher effort increases NPV and higher $\bar{V}$ reduces it. If the first (second) effect outweighs the second (first), then syndicated debt yields higher (lower) NPV. In Panels A to D and F of Table 1, overall NPV falls when financing is syndicated and debt is substituted for equity. Note the high values for $\bar{V}$ in Panels $\mathrm{A}$ to $\mathrm{D}$ and $\mathrm{F}$. Panel $\mathrm{E}$ is an exception, where syndicate financing is feasible with debt but not with equity.

Syndication in the debt financing case reduces the initial venture capitalist's financial flexibility. Since the syndicate does not allow the initial venture capitalist to hold up the entrepreneur ex post, he sets the face value of his own date-0 debt higher in order to extract as much upside as possible. This creates a debt overhang, which translates in turn to higher 
strike values (higher $\bar{V} \mathrm{~s}$ ) and to lower NPV.

According to Table 1, the initial venture capitalist should abandon syndication and switch to monopoly debt financing if faced with the parameter values in panels $\mathrm{B}$ and $\mathrm{D}$. Why is syndicate debt financing not better than monopoly debt financing? Syndicated debt should eliminate holdup problems at date 1 . One answer is that Table 1 does not include potential gains from renegotiation at date 1 before syndicate financing is raised. We discussed renegotiation for the syndicated equity case, but left it out of our calculations. Opportunities for renegotiation are rare with equity financing, and syndicated equity is more efficient than monopoly equity even when potential gains from renegotiation are ignored. With syndicated debt, opportunities for renegotiation are much more common, because of the high strike values created by the initial venture capitalist's debt holdings, and potential value gains much larger.

Other things equal, including the date- 1 strike value $\bar{V}_{1}$, financing on competitive rather than monopolistic terms at date 1 must improve effort and ex ante NPV. But it is not clear whether renegotiation is a reliable mechanism to reduce the high strike values that we have calculated for the debt syndication case. Frequent opportunities for renegotiation may also mean frequent opportunities for the incumbent venture capitalist to reassert his monopoly power. The incumbent could force renegotiation even when the startup is performing well and $V_{1}>\bar{V}_{1}$. The syndicate investors, who are unlikely to be fully informed about $V_{1}$, have no particular reason to object to renegotiation, since their investment is zero-NPV in any case. These issues, which we leave as a topic for further research, are probably second-order with equity financing, because opportunities to add value by renegotiation are rare and only occur at low values of $V_{1}$, for example in down rounds. These issues may be much more serious with syndicated debt financing.

The syndication results in Table 1 may shed some light on why venture capitalists choose to hold equity when later-stage financing is syndicated. In Panels A through D and F, syndicate financing with equity rather than debt increases both overall NPV and the NPV to the original venture capitalist. Hence, if the choice of financing can be dictated by the venture capitalist at time 0 , then he would maximize his NPV by offering equity financing to the entrepreneur. The entrepreneur does better with debt, but cannot bribe the venture capitalist to change to debt. Even if the entrepreneur had independent wealth to finance a bribe, no deal could be struck, because the change from equity to debt would decrease overall value. Panel $\mathrm{E}$ is the exception where a switch from equity to debt would make both the entrepreneur and the venture capitalist better off. ${ }^{23}$

We summarize our findings on debt versus equity in venture capital as follows. First, debt does not eliminate the holdup problem when incumbent venture capitalists can dictate the terms of later-stage financing. Second, debt financing is not generally more efficient than

\footnotetext{
${ }^{23}$ We have not explored differences between debt and equity over all possible parameter values. Thus we cannot rule out cases where a switch from equity to debt in the syndication case increases overall NPV at the venture capitalist's expense. In such cases the entrepreneur could compensate the venture capitalist for the switch, providing she has sufficient wealth. If her wealth is not sufficient, the alternative is to offer the venture capitalist some extra shares, options or warrants at date 1 . But then we have a mix of debt and equity financing, which would affect effort and value. For the use of equity securities in debt renegotiation, see Kalay and Zender (1997) and Bhattacharya and Faure-Grimaud (2001).
} 
equity. Even in the fully competitive case, switching from equity to debt sometimes adds value (in Panels $\mathrm{C}, \mathrm{E}$ and $\mathrm{F}$ of Table 1 ) and sometimes reduces value (Panels A, B and D). Third, debt financing for high-risk startups is equivalent to compensating the entrepreneur exclusively with options rather than shares. We think that the most efficient contract will be a mixture of shares and options for the entrepreneur - or equivalently, a combination of an initial share award plus additional shares conditional on high realized value for the startup. Kaplan and Strömberg (2003) document such contingent payoffs in practice. ${ }^{24}$

Contingent compensation for the entrepreneur should also help reveal the startup's value to potential syndicate investors. Recall our discussion of the modified fixed-fraction rule, in which the incumbent venture capitalist's participation in date- 1 financing can negate his incentive to over-report the value of the startup. We noted that that options or contingent share awards to the entrepreneur may be necessary to prevent a breakdown of revelation at high values of $V_{1}$.

An investigation of optimal contracts for venture capital will have to address (1) the mix of shares, options or other securities given to the entrepreneur and venture capitalists, (2) bargaining and renegotiation between incumbent venture capitalists and the entrepreneur before additional financing is raised and (3) information revelation. We believe that these three issues are interconnected. We leave them for further research.

\section{Conclusions}

As far as we know, this paper is the first to combine the main features of venture-capital contracting in a consistent formal model. As we expected, the model has no closed-form solution, except in the first-best case, so we embarked on an experiment in computational corporate finance. We show how multiple contractual provisions that are common in venture capital contracts affect the moral hazard, effort provision, asymmetric information and holdup problems in the entrepreneur-venture capital relationship. Venture capital contracting does not solve these problems indvidually but trades them off. For example, staged financing induces more efficient investment decisions in later stages but creates a potential holdup problem. A commitment to later stage syndication can alleviate the holdup problem between the entrepreneur and the initial venture capitalist but introduces information revelation problems between the incumbent venture capitalist and members of the later stage syndicate.

Venture capital financing comes with efficiency losses. We find significant underinvestment: many positive NPV-projects cannot be financed. For projects that can be financed, there can be large value losses due to under-provision of effort, even for relatively small effort costs. A commitment to syndicate financing in later stages reduces the entrepreneur's underprovision of effort, increasing overall efficiency. Syndication increases the NPVs of both the entrepreneur and the initial venture capitalist. The venture capitalist's profits increase despite taking a smaller share than in the monopoly case.

Syndicate financing is most effective when the incumbent venture capitalist's inside in-

\footnotetext{
${ }^{24}$ Contingent payoffs are implicit in our model, at least in the syndication and the fully competitive cases, because the entrepreneur's share of the firm increases as date- 1 value increases. See Figures 7 and 8 .
} 
formation is revealed through his participation in financing. However, the fixed-fraction participation rule derived by Admati and Pfleiderer (1994) does not work as a revelation mechanism in our model, because the terms of financing affect the entrepreneur's effort. A modified fixed-fraction rule, in which the incumbent's fractional participation increases as the reported value increases, can work in some cases. We suggest that a combination of the modified rule with additional contingent share awards to the entrepreneur should work generally, although a full analysis of asymmetric information and revelation will remain a topic for further research.

The startups that venture capitalists invest in are compound call options. Therefore we expected strong option-like behavior, for example a strong dependence of strike values and NPVs on the variance of final payoffs. But this expected behavior was attenuated or overridden by agency and incentive problems. We noted how increased uncertainty dampens the entrepreneur's effort, for example. This feedback is not a result of risk aversion, because the entrepreneur is assumed risk-neutral. It arises because increased uncertainty reduces the marginal value added by effort when potential value is sufficiently high.

The option-like properties of venture capital investments are also attenuated because financing is feasible only for startups that are well in the money, from a purely financial point of view. They have to be well in the money to overcome incentive problems and costs of effort. That is why all the numerical results presented in this paper assume expected potential value of $V_{0}=150$ or 200 , versus total investment of only 100 . Even with these prospects, financing may not be feasible, even with competitive syndicate financing. Note the negative NPVs in panel E of Table 1, for example.

Of course numerical results are never conclusive. One can never rule out the possibility that results would have been different with different inputs or modeling choices. But we verified our results over a wide range of inputs. Our model, though simplified, follows actual practice in venture capital. Once we simplified, our only judgment calls were the choices of the lognormal distribution for the startup's value and of exponential functions for the value added and cost of effort. We believe these assumptions are reasonable, but further research could explore alternatives.

\section{Appendix}

\subsection{Appendix 1. Solving the optimization problems.}

\subsubsection{First-best.}

Date 1: The entrepreneur's date-1 NPV is

$$
N P V_{1}^{M}=\max \left[0, \max _{x_{1}}\left(E_{1} P\left(x_{1}\right)-g_{1}\left(x_{1}\right)-I_{1}\right)\right]
$$

with first-order condition for effort $f_{0} V_{1}=\frac{g_{1}^{\prime}}{f_{1}^{\prime}}$. This implies the first-best effort level and function values

$$
\begin{aligned}
x_{1}^{\star} & =\frac{1}{\theta} \ln \left(\theta_{r} f_{0} V_{1}\right) \\
f_{1}^{\star} & =1-\left(\theta_{r} f_{0} V_{1}\right)^{-\theta_{f} / \theta} \\
g_{1}^{\star} & =\left(\theta_{r} f_{0} V_{1}\right)^{\theta_{g} / \theta}
\end{aligned}
$$


letting $\theta=\theta_{f}+\theta_{g}, \theta_{r}=\theta_{f} / \theta_{g}$. Substituting $f_{1}^{*}$ and $g_{1}^{*}$ into (14) yields

$$
N P V_{1}^{M}=\max \left[0, f_{0} V_{1}-\tilde{\theta}\left(f_{0} V_{1}\right)^{\theta_{g} / \theta}-I_{1}\right]
$$

letting $\widetilde{\theta}=\theta_{r}^{-\theta_{f} / \theta}+\theta_{r}^{\theta_{g} / \theta}$.

Investment procedes when $N P V_{1}^{M} \geq 0$. Let $\bar{V}_{1}$ be such that $N P V_{1}^{M}\left(\bar{V}_{1}\right)=0$. Then $\bar{V}_{1}$ is calculated numerically from

$$
I_{1}=f_{0} \bar{V}_{1}-\widetilde{\theta}\left(f_{0} \bar{V}_{1}\right)^{\theta_{g} / \theta}
$$

Date 0: The entrepreneur's date- $0 N P V$ is the difference between her expected date-1 $N P V$ and the $t=0$ costs of investment and effort:

$$
N P V_{0}^{M}=\max \left[0, \max _{x_{0}}\left(E_{0} N P V_{1}^{M}\left(x_{0}\right)-g_{0}\left(x_{0}\right)-I_{0}\right)\right]
$$

The NPV expectation is taken by weighting each possible $N P V_{1}^{M}$ realization (Eq. (16)) from $\bar{V}_{1}$ onwards

$$
E_{0} N P V_{1}^{M}\left(x_{0}\right)=f_{0} \int_{\bar{V}_{1}\left(x_{0}\right)}^{\infty} \Pi(V) V d V-\widetilde{\theta} f_{0}^{\theta_{g} / \theta} \int_{\bar{V}_{1}\left(x_{0}\right)}^{\infty} \Pi(V) V^{\theta_{g} / \theta} d V-I_{1} \int_{\bar{V}_{1}\left(x_{0}\right)}^{\infty} \Pi(V) d V
$$

where $\Pi(V)$ is the lognormal density. Since $N P V_{1}^{M}\left(x_{0}, \bar{V}_{1}\left(x_{0}\right)\right)=0$, the entrepreneur's first-order condition for effort reduces to

$$
E_{0}\left(N P V_{1}^{M}\left(x_{0}^{\star}\right)\right)^{\prime}=g_{0}^{\prime}\left(x_{0}^{\star}\right)
$$

with $E_{0}\left(N P V_{1}^{M}\left(x_{0}\right)\right)^{\prime}$ taken from (19)

$$
E_{0}\left(N P V_{1}^{M}\left(x_{0}\right)\right)^{\prime}=f_{0}^{\prime}\left[\int_{\bar{V}_{1}\left(x_{0}\right)}^{\infty} \Pi(V) V d V-\frac{\theta_{g} \tilde{\theta}}{\theta} f_{0}^{-\theta_{f} / \theta} \int_{\bar{V}_{1}\left(x_{0}\right)}^{\infty} \Pi(V) V^{\theta_{g} / \theta} d V\right]
$$

Change of variables on the lognormal establishes that

$$
\int_{a}^{\infty} \Pi(V) V^{k} d V=e^{\left(\frac{k^{2} \sigma^{2}}{2}+\mu k\right)} N_{(0,1)}\left(\frac{\mu-\ln a}{\sigma}+k \sigma\right)
$$

where $\mu=E(\ln V), \sigma^{2}=\operatorname{Var}(\ln V)$, and $N_{(0,1)}$ is the standard normal cdf. Using this property the entrepreneur's first-order condition simplifies to

$$
\frac{1}{\theta_{r}} e^{\theta x_{0}^{\star}}=V_{0} N_{(0,1)}\left(\phi+\frac{1}{2} \sigma\right)-e^{\left(-\frac{\theta_{f} \theta_{g} \sigma^{2}}{2 \theta^{2}}\right)} \frac{\theta_{g} \tilde{\theta}}{\theta} V_{0}^{\theta_{g} / \theta} f_{0}^{-\theta_{f} / \theta} N_{(0,1)}\left(\phi+\sigma \frac{2 \theta_{g}-\theta}{2 \theta}\right)
$$

letting $\phi=\frac{1}{\sigma} \ln \frac{V_{0}}{V_{1}}$. We solve numerically for $x_{0}^{\star}$ since $\phi=\phi\left(\bar{V}_{1}\left(x_{0}^{\star}\right)\right)$. A calculation whether $N P V_{0}^{M}\left(x_{0}^{\star}\right) \geq 0$ determines whether the initial $I_{0}+g_{0}$ investment will be made. 


\subsubsection{Monopolist case.}

Date 1: The entrepreneur's date-1 effort and NPV are similar to Eqs. (14)-(16). Firm value is multiplied by the entrepreneur's share of the project $\alpha_{1}^{M}=1-\alpha_{1}^{C}$ and $I_{1}$ drops out of her NPV term, yielding

$$
\begin{aligned}
N P V_{1}^{M}\left(\alpha_{1}^{C}\right) & =\max \left[0, \max _{x_{1}}\left(\alpha_{1}^{M} E_{1} P\left(x_{1}\right)-g_{1}\left(x_{1}\right)\right)\right] \\
x_{1}^{\star} & =\frac{1}{\theta} \ln \left(\theta_{r} \alpha_{1}^{M} f_{0} V_{1}\right) \\
f_{1}^{\star} & =1-\left(\theta_{r} \alpha_{1}^{M} f_{0} V_{1}\right)^{-\theta_{f} / \theta} \\
g_{1}^{\star} & =\left(\theta_{r} \alpha_{1}^{M} f_{0} V_{1}\right)^{\theta_{g} / \theta} \\
N P V_{1}^{M}\left(\alpha_{1}^{C}\right) & =\max \left[0, \alpha_{1}^{M} f_{0} V_{1}-\widetilde{\theta}\left(\alpha_{1}^{M} f_{0} V_{1}\right)^{\theta_{g} / \theta}\right]
\end{aligned}
$$

The venture capitalist chooses $\alpha_{1}^{C \star}$ to maximize his date $1 N P V$, equal to his share of the firm value decreased by time 1 investment costs. Plugging in $f_{1}^{\star}$ from (24) yields

$$
\begin{aligned}
N P V_{1}^{C} & =\max \left[0, \max _{\alpha_{1}^{C} \in\left(0, \alpha_{1}^{C}(\max )\right]}\left(\alpha_{1}^{C} E_{1} P\left(x_{1}^{\star}\left(\alpha_{1}^{C}\right)\right)-I_{1}\right)\right] \\
& =\max \left[0, \max _{\alpha_{1}^{C} \in\left(0, \alpha_{1}^{C}(\max )\right]}\left(\alpha_{1}^{C} f_{0} V_{1}-\theta_{r}^{-\theta_{f} / \theta}\left(f_{0} V_{1}\right)^{\theta g} / \theta \alpha_{1}^{C}\left(1-\alpha_{1}^{C}\right)^{-\theta_{f} / \theta}-I_{1}\right)\right]
\end{aligned}
$$

The venture capitalist operates subject to the entrepreneur's participation constraint of $N P V_{1}^{M}\left(\alpha_{1}^{C}\right) \geq 0$. The maximum $\alpha_{1}^{C}$ share he can take is obtained by setting the last term in (25) equal to zero. This yields

$$
\alpha_{1}^{C}(\max )=1-\alpha_{1}^{M}(\min )=1-\frac{\tilde{\theta}^{\theta / \theta_{f}}}{f_{0} V_{1}}
$$

the limit point for $\alpha_{1}^{C}$ in (26). The unconstrained first-order condition for $\alpha_{1}^{C}$ is:

$$
\left(\theta_{r} f_{0} V_{1}\right)^{\theta_{f} / \theta}=\left(1-\alpha_{1}^{C \star}\right)^{-\theta_{f} / \theta-1}\left(1-\frac{\theta_{g}}{\theta} \alpha_{1}^{C \star}\right)
$$

If $\alpha_{1}^{C \star} \in\left[0, \alpha_{1}^{C}(\max )\right]$, the venture capitalist chooses the unconstrained value; if not, he assigns $\alpha_{1}^{C}(\max ) .^{25}$

However, in most parameterizations the constraint never binds. That is, $\overline{V_{1}}$, the continuation point, is typically high enough that the entrepreneur's participation constraint is always slack. For large $V_{1}, \alpha_{1}^{C \star}$ grows more slowly than $\alpha_{1}^{C}(\max )$, so it is only for small $\bar{V}_{1}$

\footnotetext{
${ }^{25}$ This follows because $N P V_{1}^{C}$ is concave in $\alpha_{1}^{C} \cdot \alpha_{1}^{M}(\mathrm{~min})$ may be greater than 1 if $f_{0}$ is small or the $V_{1}$ realization is low. Liquidation would ensue.
} 
(which result from small $I_{1}$ ) that the constraint may bind. For realistic parameterizations, the entrepreneur enjoys positive $N P V$ everywhere past (and including) $\bar{V}_{1} \cdot{ }^{26}$

Since the venture capitalist typically hits his participation constraint first, his $N P V$ determines $\bar{V}_{1}$. We compute $\bar{V}_{1}^{C}$ by looking for the pair $\left(\bar{V}_{1}^{C}, \alpha_{1}^{C \star}\left(\bar{V}_{1}^{C}\right)\right)$ that sets $N P V_{1}^{C}=$ 0. This pair solves, from Eq. (26),

$$
I_{1}=\alpha_{1}^{C \star}\left(\bar{V}_{1}^{C}\right) f_{0} \bar{V}_{1}^{C}-\left(f_{0} \bar{V}_{1}^{C}\right)^{\theta_{g} / \theta} \alpha_{1}^{C \star}\left(\bar{V}_{1}^{C}\right)\left(\theta_{r}\left(1-\alpha_{1}^{C \star}\left(\bar{V}_{1}^{C}\right)\right)\right)^{-\theta_{f} / \theta}
$$

and from Eq. (28)

$$
\left(\theta_{r} f_{0} \bar{V}_{1}^{C}\right)^{\theta_{f} / \theta}=\left(1-\alpha_{1}^{C \star}\left(\bar{V}_{1}^{C}\right)\right)^{-\theta_{f} / \theta-1}\left(1-\frac{\theta_{g}}{\theta} \alpha_{1}^{C \star}\left(\bar{V}_{1}^{C}\right)\right)
$$

Solving this system of equations implies

$$
\bar{V}_{1}^{C}=\frac{I_{1}\left(1-\frac{\theta_{g}}{\theta} \alpha_{1}^{C \star}\left(\bar{V}_{1}^{C}\right)\right)}{\frac{\theta_{f}}{\theta} f_{0}\left(\alpha_{1}^{C \star}\left(\bar{V}_{1}^{C}\right)\right)^{2}}
$$

after first solving for $\alpha_{1}^{C \star}\left(\bar{V}_{1}^{C}\right)$ numerically from

$$
I_{1}=\frac{\frac{\theta_{g}}{\theta}\left(\alpha_{1}^{C \star}\left(\bar{V}_{1}^{C}\right)\right)^{2}\left(1-\frac{\theta_{g}}{\theta} \alpha_{1}^{C \star}\left(\bar{V}_{1}^{C}\right)\right)^{\frac{1}{\theta_{r}}}}{\left(1-\alpha_{1}^{C \star}\left(\bar{V}_{1}^{C}\right)\right)^{\left(1+\theta / \theta_{f}\right)}}
$$

Investment occurs if $V_{1}>\bar{V}_{1}^{C}$.

Date 1: The entrepreneur's date 0 value is

$$
N P V_{0}^{M}=\max \left[0, \max _{x_{0}}\left(E_{0} N P V_{1}^{M}\left(x_{0}\right)-g_{0}\left(x_{0}\right)\right)\right]
$$

with first-order condition

$$
E_{0}\left(N P V_{1}^{M}\left(x_{0}^{\star}\right)\right)^{\prime}=\Pi\left(\bar{V}_{1}^{C}\right) N P V_{1}^{M}\left(f_{0}^{\star}, \bar{V}_{1}^{C}\right) \bar{V}_{1}^{C \prime}+g_{0}^{\prime}\left(x_{0}^{\star}\right)
$$

To compute $\left(N P V_{1}^{M}\left(x_{0}\right)\right)^{\prime}$, we need the formula for $\frac{\partial \alpha_{1}^{C \star}}{\partial x_{0}}$ or $\alpha_{1}^{C \star \prime}$. Using the implicit function theorem on Eq. (28) yields

$$
\alpha_{1}^{C \star \prime}=\frac{f_{0}^{\prime}\left(1-\alpha_{1}^{C \star}\right)\left(1-\frac{\theta_{g}}{\theta} \alpha_{1}^{C \star}\right)}{f_{0}\left(2-\frac{\theta_{g}}{\theta} \alpha_{1}^{C \star}\right)}
$$

\footnotetext{
${ }^{26}$ One can look at the entrepreneur's positive NPV intuitively or mathematically. Intuitively, the venture capitialist is better off when the entrepreneur has a higher incentive to provide effort. $\alpha_{1}^{C}(\max )$ is generally very high, and venture capitalist does better by taking a smaller than maximum share.

Mathematically, the continuation point $\bar{V}_{1}$ is determined by the venture capitalist's NPV because of the additive investment cost function. Since $I_{1}$ does not affect $F O C_{1}^{C}$ or $F O C_{1}^{M}$, by altering $I_{1}$ one alters the venture capitalist's profitability without changing the optimal $\alpha_{1}^{C \star}$ and the entrepreneur's profitability. Reasonable $I_{1}$ is high enough to make the venture capitalist's NPV surpass 0 without causing the entrepreneur's to fall below 0 .
} 
Deriving entrepreneur value (Eq. (25)) with respect to initial effort, taking its expectation over all possible $V_{1}$ realizations from $\bar{V}_{1}^{C}$ onwards, and using (35) yields the left-hand side term in (34):

$$
E_{0}\left(N P V_{1}^{M}\left(x_{0}\right)\right)^{\prime}=f_{0}^{\prime}\left[\int_{\bar{V}_{1}\left(x_{0}\right)}^{\infty} \Pi(V) \frac{\alpha_{1}^{M \star} V}{\left(2-\frac{\theta_{g}}{\theta} \alpha_{1}^{C \star}\right)} d V-\frac{\theta_{g}}{\theta} \tilde{\theta} f_{0}^{-\theta_{f} / \theta} \int_{\bar{V}_{1}\left(x_{0}\right)}^{\infty} \Pi(V) \frac{\left(\alpha_{1}^{M \star} V\right)^{\theta_{g} / \theta}}{\left(2-\frac{\theta_{g}}{\theta} \alpha_{1}^{C \star}\right)} d V\right]
$$

The middle term in Eq. (34) is evaluated as follows. $N P V_{1}^{M}$ is found plugging $\bar{V}_{1}^{C}$ and $\alpha_{1}^{C \star}\left(\bar{V}_{1}^{C}\right)$ from Eq.s (31) and (32) into Eq. (25). $\Pi\left(\bar{V}_{1}^{C}\right)$ is taken from the lognormal distribution. For $\bar{V}_{1}^{C \prime}$, the implicit function theorem on Eq. (31) and $\alpha_{1}^{C \star \prime}$ from Eq. (35) yield

$$
\bar{V}_{1}^{C \prime}=\frac{-f_{0}^{\prime} \bar{V}_{1}^{C}}{f_{0} \alpha_{1}^{C \star}}
$$

We solve numerically for $x_{0}^{\star}$ from Eq. (34). We evaluate the integrals point-by-point, ending the summation at 6 times the standard deviation of $V_{1}$. Given $x_{0}^{*}$, and assuming that the entrepreneur wants to continue, i.e. $N P V_{0}^{M}\left(x_{0}^{*}\right)>0$, the venture capitalist decides whether to invest. His option is worth

$$
N P V_{0}^{C}=\max \left[0, E_{0} N P V_{1}^{C}\left(x_{0}^{\star}\right)-I_{0}\right]
$$

with

$$
E_{0} N P V_{1}^{C}\left(x_{0}^{\star}\right)=\left[\begin{array}{c}
f_{0}^{\star} \int_{\bar{V}_{1}\left(x_{0}^{\star}\right)}^{\infty} \Pi(V) \alpha_{1}^{C \star} V d V \\
-\theta_{r}^{-\theta_{f} / \theta} f_{0}^{\star_{g} / \theta} \int_{\bar{V}_{1}\left(x_{0}^{\star}\right)}^{\infty} \Pi(V) \alpha_{1}^{C \star}\left(1-\alpha_{1}^{C \star}\right)^{-\theta_{f} / \theta} V^{\theta_{g} / \theta} d V-I_{1} \int_{\bar{V}_{1}\left(x_{0}^{\star}\right)}^{\infty} \Pi(V) d V
\end{array}\right]
$$

If $N P V_{0}^{C}>0$ the venture capitalist will provide funding.

\subsubsection{Monopolist case, no staging.}

Date 1: The entrepreneur's date-1 NPV and effort is determined as in Eqs. (23-24) except that $\alpha_{1}^{M}$, the manager's date 1 project share, has already been negotiated and set at date 0 . Denoting this as $\alpha_{1}^{M}=\alpha_{0}^{M \star}$, the manager's date-1 NPV simplifies to

$$
N P V_{1}^{M}=\max \left[0, \alpha_{0}^{M \star} f_{0} V_{1}-\tilde{\theta}\left(\alpha_{0}^{M \star} f_{0} V_{1}\right)^{\theta_{g} / \theta}\right]
$$

Because all funding $\left(I_{0}+I_{1}\right)$ has been supplied upfront, the venture capitalist no longer has any decisions to make at $t=1$. The entrepreneur now makes the continuation decision, so that $\overline{V_{1}}$, the continuation point, is found by setting $N P V_{1}^{M}=0$. This yields

$$
\overline{V_{1}^{M}}=\frac{\tilde{\theta}^{\theta / \theta_{f}}}{\alpha_{0}^{M \star} f_{0}}
$$

Letting $\alpha_{1}^{C}=\alpha_{0}^{C \star}$, the venture capitalist's $N P V$ (26) simplifies to

$$
N P V_{1}^{C}=\left\{\begin{array}{cl}
0 & \text { if } V_{1}<\bar{V}_{1}^{M} \\
\alpha_{0}^{C \star} f_{0} V_{1}-\alpha_{0}^{C \star}\left(f_{0} V_{1}\right)^{\theta_{g} / \theta}\left(\theta_{r}\left(1-\alpha_{0}^{C \star}\right)\right)^{-\theta_{f} / \theta} & \text { if } V_{1} \geq \bar{V}_{1}^{M}
\end{array}\right.
$$


Date 0: At date 0, the venture capitalist decides his ultimate project share $\alpha_{0}^{C *}$ and the entrepreneur decides how much effort to exert. For a given $\alpha_{0}^{C}$, the entrepreneur's value is

$$
N P V_{0}^{M}\left(\alpha_{0}^{C}\right)=\max \left[0, \max _{x_{0}}\left(E_{0} N P V_{1}^{M}\left(x_{0}\left(\alpha_{0}^{C}\right), \alpha_{0}^{C}\right)-g_{0}\left(x_{0}\left(\alpha_{0}^{C}\right)\right)\right]\right.
$$

The expectation of the entrepreneur's date-1 NPV is found by weighting (40) over possible $V_{1}$ realizations. Again letting $\alpha_{1}^{M}=\alpha_{0}^{M}$ and using the strike value from (41), we obtain

$$
E_{0} N P V_{1}^{M}\left(x_{0}\left(\alpha_{0}^{C}\right), \alpha_{0}^{C}\right)=\alpha_{0}^{M} f_{0} \int_{\bar{V}_{1}^{M}}^{\infty} \Pi(V) V d V-\widetilde{\theta}\left(\alpha_{0}^{M} f_{0}\right)^{\theta_{g} / \theta} \int_{\bar{V}_{1}^{M}}^{\infty} \Pi(V) V^{\theta_{g} / \theta} d V
$$

Change of variables on the lognormal (as in the first-best case) establishes that

$$
\begin{aligned}
E_{0} N P V_{1}^{M}\left(x_{0}\left(\alpha_{0}^{C}\right), \alpha_{0}^{C}\right)= & \alpha_{0}^{M} f_{0} V_{0} N_{(0,1)}\left(\phi+\frac{1}{2} \sigma\right) \\
& -e^{\left(\frac{-\theta_{f} \theta_{g} \sigma^{2}}{2 \theta^{2}}\right)} \tilde{\theta}\left(\alpha_{0}^{M} f_{0} V_{0}\right)^{\theta_{g} / \theta} N_{(0,1)}\left(\phi+\sigma \frac{2 \theta_{g}-\theta}{2 \theta}\right)
\end{aligned}
$$

leading to the entrepreneur's first-order condition for effort

$$
\frac{1}{\theta_{r}} e^{\theta x_{0}^{\star}}=\alpha_{0}^{M} V_{0} N_{(0,1)}\left(\phi+\frac{1}{2} \sigma\right)-e^{\left(-\frac{\theta_{f} \theta_{g} \sigma^{2}}{2 \theta^{2}}\right)} \frac{\theta_{g} \tilde{\theta}}{\theta}\left(\alpha_{0}^{M} V_{0}\right)^{\theta_{g} / \theta} f_{0}^{-\theta_{f} / \theta} N_{(0,1)}\left(\phi+\sigma \frac{2 \theta_{g}-\theta}{2 \theta}\right)
$$

letting $\phi=\frac{1}{\sigma} \ln \frac{V_{0}}{\bar{V} 1^{M}}$. Again we solve numerically for $x_{0}^{\star}$.

The venture capitalist anticipates $x_{0}^{\star}\left(\alpha_{0}^{C}\right)$ when he sets $\alpha_{0}^{C}$. He must restrict his search to $\alpha_{0}^{C} \in\left(0, \alpha_{0}^{C}(\max )\right]$, where $\alpha_{0}^{C}(\max )$ is such that

$$
E_{0} N P V_{1}^{M}\left(x_{0}^{\star}\left(\alpha_{0}^{C}(\max )\right), \alpha_{0}^{C}(\max )\right)-g_{0}\left(x_{0}^{\star}\left(\alpha_{0}^{C}(\max )\right)\right)=0
$$

This constraint rarely binds, and $\alpha_{0}^{C *}$ will be chosen to maximize

$$
N P V_{0}^{C}=\max \left[0, \max _{\alpha_{0}^{C}(\max ) \geq \alpha_{0}^{C}} E_{0} N P V_{1}^{C}\left(x_{0}^{\star}\left(\alpha_{0}^{C}\right), \alpha_{0}^{C}\right)-I_{0}-I_{1}\right]
$$

Taking the expectation of (42) and using $x_{0}^{\star}$ from the entrepreneur's maximization and the strike value from (41), we obtain

$$
\begin{aligned}
E_{0} N P V_{1}^{C}\left(x_{0}^{\star}\left(\alpha_{0}^{C}\right), \alpha_{0}^{C}\right)= & \alpha_{0}^{C} f_{0} \int_{\bar{V}_{1}^{M}}^{\infty} \Pi(V) V d V \\
& -\alpha_{0}^{C}\left(1-\alpha_{0}^{C}\right)^{-\theta_{f} / \theta} f_{0}^{\theta_{g} / \theta} \theta_{r}^{-\theta_{f} / \theta} \int_{\bar{V}_{1}^{M}}^{\infty} \Pi(V) V^{\theta_{g} / \theta} d V \\
= & \alpha_{0}^{C} f_{0} V_{0} N_{(0,1)}\left(\phi+\frac{1}{2} \sigma\right)- \\
& \alpha_{0}^{C}\left(\theta_{r}\left(1-\alpha_{0}^{C}\right)\right)^{-\theta_{f} / \theta}\left(f_{0} V_{0}\right)^{\theta_{g} / \theta} e^{\left(\frac{-\theta_{f} \theta_{g^{2}}}{2 \theta^{2}}\right)} N_{(0,1)}\left(\phi+\sigma \frac{2 \theta_{g}-\theta}{2 \theta}\right)
\end{aligned}
$$


again using change of variables and letting $\phi=\frac{1}{\sigma} \ln \frac{V_{0}}{\bar{V}_{1}^{M}}$. We solve for $\alpha_{0}^{C *}$ numerically, since $f_{0}=f_{0}\left(x_{0}^{\star}\left(\alpha_{0}^{C}\right)\right)$. If $N P V_{0}^{C} \geq 0$ investment will proceed.

\subsubsection{Syndicate case.}

Date 1: At date 1, for a given share $\alpha_{1}^{M}$, the entrepreneur's NPV and maximization problem are the same as before. We obtain $x_{1}^{\star}, f_{1}^{\star}, g_{1}^{\star}$, and $N P V_{1}^{M}\left(\alpha_{1}^{S}\right)$ exactly as in Eq.s (23)-(25), but where $\alpha_{1}^{M}=\alpha_{0}^{M}\left(1-\alpha_{1}^{S}\right)$. The share given to the outside syndicate, $\alpha_{1}^{S}$, is determined by setting $N P V_{1}^{S}$ equal to zero, which yields

$$
\begin{aligned}
I_{1} & =\alpha_{1}^{S} f_{0} f_{1}^{\star}\left(\alpha_{1}^{S}\right) V_{1} \\
& =\alpha_{1}^{S} f_{0} V_{1}-\alpha_{1}^{S}\left(1-\alpha_{1}^{S}\right)^{-\theta_{f} / \theta}\left(f_{0} V_{1}\right)^{\theta_{g} / \theta}\left(\theta_{r} \alpha_{0}^{M}\right)^{-\theta_{f} / \theta}
\end{aligned}
$$

after substituting $f_{1}^{\star}$. This is solved numerically for $\alpha_{1}^{S}$.

We solve for $\bar{V}_{1}$ using the same procedure as in the monopolistic venture capitalist scenario. As previously, $\bar{V}_{1}$ may imply that $N P V_{1}^{M}\left(\bar{V}_{1}\right)>0$ or that $N P V_{1}^{M}\left(\bar{V}_{1}\right)=0$. Again, for realistic values of $I_{1}$ the entrepreneur's participation constraint is always slack. Therefore we identify $\bar{V}_{1}$ by finding the point where the maximum value to the syndicate is zero. At this point the value of $\alpha_{1}^{S}$ implied by the syndicate's zero-profit condition (51) is equal to the value implied by the syndicate's hypothetical maximization problem. The syndicate's hypothetical $F O C_{1}^{S}$ is: ${ }^{27}$

$$
\left(\theta_{r} \alpha_{0}^{M} f_{0} V_{1}\right)^{\theta_{f} / \theta}=\left(1-\alpha_{1}^{S \star}\right)^{-\theta_{f} / \theta-1}\left(1-\frac{\theta_{g}}{\theta} \alpha_{1}^{S \star}\right)
$$

We solve for $\bar{V}_{1}$ by finding the pair $\left(\bar{V}_{1}^{S}, \alpha_{1}^{S}\left(\bar{V}_{1}^{S}\right)\right)$ such that $\alpha_{1}^{S}\left(\bar{V}_{1}^{S}\right)=\alpha_{1}^{S \star}\left(\bar{V}_{1}^{S}\right)$. We compute $\alpha_{1}^{S}\left(\bar{V}_{1}^{S}\right)$ numerically from

$$
I_{1} \alpha_{0}^{M}=\frac{\frac{\theta_{g}}{\theta}\left(\alpha_{1}^{S}\left(\bar{V}_{1}^{S}\right)\right)^{2}\left(1-\frac{\theta_{g}}{\theta} \alpha_{1}^{S}\left(\bar{V}_{1}^{S}\right)\right)^{\frac{1}{\theta_{r}}}}{\left(1-\alpha_{1}^{S}\left(\bar{V}_{1}^{S}\right)\right)^{1+\theta / \theta_{f}}}
$$

Using FOC $C_{1}^{S}$ (Eq. (53)) once again, we compute $\bar{V}_{1}^{S}$ as

$$
\bar{V}_{1}^{S}=\frac{I_{1}\left(1-\frac{\theta_{g}}{\theta} \alpha_{1}^{S}\left(\bar{V}_{1}^{S}\right)\right)}{\frac{\theta_{f}}{\theta} f_{0}\left(\alpha_{1}^{S}\left(\bar{V}_{1}^{S}\right)\right)^{2}}
$$

These two expressions are nearly identical to Eq.s (31) and (32), pertaining to the monopolistic venture capitalist's breakeven point. The sole difference in the expressions is the presence of $\alpha_{0}^{M}$, the entrepreneur's initial project share, on the left-hand side of Eq. (54).

\footnotetext{
${ }^{27}$ In general there will be two solutions to the zero-profit equation, $\underline{\alpha}_{1}^{S}$ and $\bar{\alpha}_{1}^{S}$. $\bar{\alpha}_{1}^{S}$ is the maximum share which can be given to the syndicate and still return $N P V^{S}=0 ; \underline{\alpha}_{1}^{S}$ is the minimum share. For $\alpha_{1}^{S} \in\left(\underline{\alpha}_{1}^{S}, \bar{\alpha}_{1}^{S}\right)$, the syndicate enjoys positive expected profits (indeed these two values can be thought of as bounds for the profit-maximizing share). When $V_{1}=\bar{V}_{1}$, then $\underline{\alpha}_{1}^{S}=\alpha_{1}^{S \star}=\bar{\alpha}_{1}^{S}$. We use $\underline{\alpha}_{1}^{S}$ in all computations.
} 
This lowers $\alpha_{1}^{S}\left(\bar{V}_{1}^{S}\right)$, implying a higher $\bar{V}_{1}^{S}$ than in the monopolistic venture capitalist scenario. Investment at date 1 occurs for $V_{1}>\bar{V}_{1}^{S}$.

Date 0: At date 0, the venture capitalist decides his project share $\alpha_{0}^{C *}$ and the entrepreneur decides how much effort to exert. For a given $\alpha_{0}^{C}$, the entrepreneur's value is

$$
N P V_{0}^{M}\left(\alpha_{0}^{C}\right)=\max \left[0, \max _{x_{0}}\left(E_{0} N P V_{1}^{M}\left(x_{0}\left(\alpha_{0}^{C}\right), \alpha_{0}^{C}\right)-g_{0}\left(x_{0}\left(\alpha_{0}^{C}\right)\right)\right]\right.
$$

Using the solutions for $f_{1}^{\star}, g_{1}^{\star}$, and $\alpha_{1}^{S}$ from Eqs. (24) and (51), we get

$$
\begin{aligned}
E_{0} N P V_{1}^{M}\left(x_{0}\left(\alpha_{0}^{C}\right), \alpha_{0}^{C}\right)= & \alpha_{0}^{M} f_{0} \int_{\bar{V}_{1}\left(x_{0}\left(\alpha_{0}^{C}\right), \alpha_{0}^{C}\right)}^{\infty} \Pi(V) V\left(1-\alpha_{1}^{S}\right) d V \\
& -\widetilde{\theta}\left(\alpha_{0}^{M} f_{0}\right)^{\theta_{g} / \theta} \int_{\bar{V}_{1}\left(x_{0}\left(\alpha_{0}^{C}\right), \alpha_{0}^{C}\right)}^{\infty} \Pi(V)\left(V\left(1-\alpha_{1}^{S}\right)\right)^{\theta_{g} / \theta} d V
\end{aligned}
$$

We solve for $x_{0}^{\star}\left(\alpha_{0}^{C}\right)$ numerically, exactly as in the monopolistic venture capitalist case, only using the lower $\alpha_{1}^{S}$ share in the entrepreneur's NPV term.

The venture capitalist anticipates $x_{0}^{\star}\left(\alpha_{0}^{C}\right)$ when he sets $\alpha_{0}^{C}$. He must restrict his search to $\alpha_{0}^{C} \in\left(0, \alpha_{0}^{C}(\max )\right]$, where $\alpha_{0}^{C}(\max )$ is such that

$$
E_{0} N P V_{1}^{M}\left(x_{0}^{\star}\left(\alpha_{0}^{C}(\max )\right), \alpha_{0}^{C}(\max )\right)-g_{0}\left(x_{0}^{\star}\left(\alpha_{0}^{C}(\max )\right)\right)=0
$$

This constraint rarely binds, and $\alpha_{0}^{C *}$ will be chosen to maximize

$$
N P V_{0}^{C}=\max \left[0, \underset{\alpha_{0}^{C}}{\max _{\alpha_{0}^{C}(\max )}} E_{0} N P V_{1}^{C}\left(x_{0}^{\star}\left(\alpha_{0}^{C}\right), \alpha_{0}^{C}\right)-I_{0}\right]
$$

Using the solutions for $f_{1}^{\star}, g_{1}^{\star}$, and $\alpha_{1}^{S}$ from Eq.s (24) and (51), and $x_{0}^{\star}$ from the entrepreneur's maximization, we obtain

$$
\begin{aligned}
E_{0} N P V_{1}^{C}\left(x_{0}^{\star}\left(\alpha_{0}^{C}\right), \alpha_{0}^{C}\right)= & \alpha_{0}^{C} f_{0} \int_{\bar{V}_{1}\left(x_{0}^{\star}\left(\alpha_{0}^{C}\right), \alpha_{0}^{C}\right)}^{\infty} \Pi(V) V\left(1-\alpha_{1}^{S}\right) d V \\
& -\alpha_{0}^{C}\left(1-\alpha_{0}^{C}\right)^{-\theta_{f} / \theta} f_{0}^{\theta_{g} / \theta} \theta_{r}^{-\theta_{f} / \theta} \int_{\bar{V}_{1}\left(x_{0}^{\star}\left(\alpha_{0}^{C}\right), \alpha_{0}^{C}\right)}^{\infty} \Pi(V)\left(V\left(1-\alpha_{1}^{S}\right)\right)^{\theta_{g} / \theta} d V
\end{aligned}
$$

We solve for $\alpha_{0}^{C *}$ numerically, again evaluating the integrals point-by-point, ending the summation at 6 standard deviations of $V_{1}$. If $N P V_{0}^{C} \geq 0$ investment will proceed.

\subsection{Appendix 2. Syndicate Financing: Asymmetric Information.}

\subsubsection{The Case of no effort at $t=1$.}

Consider a project where there is no date 1 effort, only the $I_{1}$ cost. In expectation the project is worth (letting $f_{0}=1$ for simplicity) $P=V_{1}-I_{1}$. The original venture capitalist's exposure is 


$$
N P V_{1}^{C}=\alpha_{1}^{C} V_{1}-\beta I_{1}
$$

where

$$
\alpha_{1}^{C}=\alpha_{0}^{C}+\alpha_{1}^{S}\left(\beta-\alpha_{0}^{C}\right)
$$

If the truth is reported in equilibrium, then

$$
\alpha_{1}^{S}=\frac{I_{1}}{V_{1}}=\frac{I_{1}}{\hat{V}_{1}}=\hat{\alpha}_{1}^{S}
$$

To make the capitalist indifferent between telling the truth and lying about $V_{1}$, we take the derivative of Eq. (61) with respect to $\hat{V}_{1}$ and set it equal to zero which yields

$$
V_{1} \frac{\partial \alpha_{1}^{C}}{\partial \hat{V}_{1}}=I_{1} \frac{\partial \beta}{\partial \hat{V}_{1}}
$$

or, using $\hat{\alpha}_{1}^{S} \hat{V}_{1}=I_{1}$,

$$
V_{1}\left(\beta-\alpha_{0}^{C}\right) \frac{-I_{1}}{\hat{V}_{1}^{2}}+I_{1} \frac{\partial \beta}{\partial \hat{V}_{1}}=I_{1} \frac{\partial \beta}{\partial \hat{V}_{1}}
$$

The only solution is $\beta=\alpha_{0}^{C}$. Similarly, we can derive the solution when $I_{1}$ can vary (for instance if $I_{1}$ influences the probability of favorable $V_{2}$ realizations).

\subsubsection{The Case of $t=1$ effort by the entrepreneur.}

When we have endogenous effort,

$$
N P V_{1}^{C}=\alpha_{1}^{C} f_{1} V_{1}-\beta I_{1}
$$

and

$$
\alpha_{1}^{S}=\frac{I_{1}}{f_{1} V_{1}}=\frac{I_{1}}{f_{1} \hat{V}_{1}}=\hat{\alpha}_{1}^{S}
$$

Differentiating by $\hat{V}_{1}$, we obtain

$$
V_{1}\left[f_{1} \frac{\partial \alpha_{1}^{C}}{\partial \hat{V}_{1}}+\alpha_{1}^{C} \frac{\partial f_{1}}{\partial \hat{V}_{1}}\right]=I_{1} \frac{\partial \beta}{\partial \hat{V}_{1}}
$$

or

$$
V_{1} f_{1} \frac{-I_{1}}{\hat{f}_{1} \hat{V}_{1}}\left[\frac{1}{\hat{f}_{1}} \frac{\partial f_{1}}{\partial \hat{V}_{1}}+\frac{1}{\hat{V}_{1}}\right]\left(\beta-\alpha_{0}^{C}\right)+I_{1} \frac{\partial \beta}{\partial \hat{V}_{1}}+V_{1} \alpha_{1}^{C} \frac{\partial f_{1}}{\partial \hat{V}_{1}}=I_{1} \frac{\partial \beta}{\partial \hat{V}_{1}}
$$

Enforcing $\hat{V}_{1}=V_{1}$ and using $\alpha_{1}^{S} f_{1} V_{1}=I_{1}$, this reduces to

$$
\left(\beta-\alpha_{0}^{C}\right) \frac{I_{1}}{V_{1}}=\frac{\partial f_{1}}{\partial \hat{V}_{1}}\left(V_{1} \alpha_{1}^{C}-V_{1}\left(\beta-\alpha_{0}^{C}\right) \alpha_{1}^{S}\right)=V_{1} \alpha_{0}^{C} \frac{\partial f_{1}}{\partial \hat{V}_{1}}
$$

that is

$$
\frac{\alpha_{1}^{C}-\alpha_{0}^{C}}{\alpha_{0}^{C}}=\frac{V_{1}}{f_{1}} \frac{\partial f_{1}}{\partial \hat{V}_{1}}
$$


First we note that if the effort did not change with $V_{1}$, the right-hand side would equal zero requiring again that $\alpha_{1}^{C}=\alpha_{0}^{C}$ or $\beta=\alpha_{0}^{C}$. However when $\frac{\partial f_{1}}{\partial \hat{V}_{1}}>0, \alpha_{1}^{C}$ must be greater than $\alpha_{0}^{C}$ in order to prevent overreporting of $V_{1}$. The gap between $\alpha_{1}^{C}$ and $\alpha_{0}^{C}$ is responsible for the under-reporting motive, because for high $V_{1}$ realizations the venture capitalist can increase his share of the project, relative to $\alpha_{0}^{C}$, on an $N P V>0$ basis.

\subsection{Appendix 3:}

\subsubsection{Monopolist debt financing.}

Date-2: The final payouts in the debt financing case are options on final firm value:

$$
\begin{gathered}
N P V_{2}^{M}=\max \left(0, f_{0} f_{1} V_{2}-K_{1}\right) \\
N P V_{2}^{C}=f_{0} f_{1} V_{2}-\max \left(0, f_{0} f_{1} V_{2}-K_{1}\right)
\end{gathered}
$$

Let $\bar{V}_{2}$ identify the point at which the entrepreneur begins receiving cashflows or

$$
\bar{V}_{2}=\frac{K_{1}}{f_{0} f_{1}}
$$

Date-1: The entrepreneur's date-1 effort and NPV must be solved for numerically with debt financing. The entrepreneur's NPV is the probability weighted expectation of her $t=2$ payouts past $\bar{V}_{2}$. That is

$$
N P V_{1}^{M}\left(K_{1}, x_{1}\right)=f_{0} \int_{\bar{V}_{2}\left(x_{1}\right)}^{\infty} \Pi(V) f_{1}\left(x_{1}\right) V d V-K_{1} \int_{\bar{V}_{2}\left(x_{1}\right)}^{\infty} \Pi(V) d V-g_{1}\left(x_{1}\right)
$$

Change of variables on the lognormal establishes that

$$
N P V_{1}^{M}\left(K_{1}\right)=\max \left[0, \max _{x_{1}}\left(f_{0} f_{1} V_{1} N_{(0,1)}\left(\phi+\frac{\sigma}{2}\right)-K_{1} N_{(0,1)}\left(\phi-\frac{\sigma}{2}\right)-g_{1}\left(x_{1}\right)\right)\right]
$$

where $N_{(0,1)}$ is standard normal cdf and $\phi=\frac{1}{\sigma} \ln \frac{V_{1}}{\bar{V}_{2}}$. We solve numerically for $x_{1}^{\star}$ since $\phi=\phi\left(\bar{V}_{2}\left(x_{1}^{\star}\right)\right)$.

The venture capitalist chooses $K_{1}^{\star}$ to maximize his date $1 N P V$, anticipating $f_{1}^{\star}\left(K_{1}\right)$ from the entrepreneur's maximization. The venture capitalist's NPV is derived similarly to the entrepreneur's, yielding

$$
N P V_{1}^{C}=\max \left[0, \max _{K_{1} \in\left(0, K_{1}(\max )\right]}\left(f_{0} f_{1} V_{1}\left(1-N_{(0,1)}\left(\phi+\frac{\sigma}{2}\right)\right)+K_{1} N_{(0,1)}\left(\phi-\frac{\sigma}{2}\right)-I_{1}\right)\right]
$$

As before, the venture capitalist operates subject to the entrepreneur's participation constraint of $N P V_{1}^{M}\left(K_{1}\right) \geq 0$. The maximum $K_{1}$ level he can take is obtained numerically, as is $K_{1}^{\star}$. If $K_{1}^{\star} \in\left[0, K_{1}(\max )\right]$, the venture capitalist chooses the unconstrained value; if not, he assigns $K_{1}(\max )$.

Since we impose that $N P V_{1}^{M}\left(K_{1}\right) \geq 0$, we solve for the continuation point $\bar{V}_{1}^{C}$ by setting the venture capitalist's maximized $N P V$ from (76) to zero. Investment occurs if $V_{1}>\bar{V}_{1}^{C}$. 
Date-0: The entrepreneur's date 0 value is

$$
N P V_{0}^{M}=\max \left[0, \max _{x_{0}}\left(E_{0} N P V_{1}^{M}\left(x_{0}\right)-g_{0}\left(x_{0}\right)\right)\right]
$$

where

$$
\begin{aligned}
E_{0} N P V_{1}^{M}\left(x_{0}\right)= & f_{0} \int_{\bar{V}_{1}^{C}}^{\infty} \Pi(V) f_{1}^{\star} V N_{(0,1)}\left(\phi+\frac{\sigma}{2}\right) d V \\
& -\int_{\bar{V}_{1}^{C}}^{\infty} \Pi(V) K_{1}^{\star} N_{(0,1)}\left(\phi-\frac{\sigma}{2}\right) d V-\int_{\bar{V}_{1}^{C}}^{\infty} \Pi(V) g_{1}^{*} d V
\end{aligned}
$$

Recall that each $V_{1}$ realization implies $K_{1}^{\star}\left(V_{1}\right), f_{1}^{\star}\left(K_{1}\left(V_{1}\right)\right)$, and $\phi\left(\bar{V}_{2}\left(K_{1}^{\star}, f_{1}^{\star}\right)\right)$. We solve for $x_{0}^{\star}$ numerically, evaluating the integrals point-by-point, ending the summation at 6 times the standard deviation of $V_{1}$.

Given $x_{0}^{*}$, and assuming that the entrepreneur wants to continue, i.e. $\operatorname{NP}_{0}^{M}\left(x_{0}^{*}\right)>0$, the venture capitalist decides whether to invest. His option is worth

$$
N P V_{0}^{C}=\max \left[0, E_{0} N P V_{1}^{C}\left(x_{0}^{\star}\right)-I_{0}\right]
$$

with

$$
\begin{aligned}
E_{0} N P V_{1}^{C}\left(x_{0}^{\star}\right)= & f_{0} \int_{\bar{V}_{1}^{C}}^{\infty} \Pi(V) f_{1}^{\star} V\left(1-N_{(0,1)}\left(\phi+\frac{\sigma}{2}\right)\right) d V \\
& +\int_{\bar{V}_{1}^{C}}^{\infty} \Pi(V) K_{1}^{\star} N_{(0,1)}\left(\phi-\frac{\sigma}{2}\right) d V-\int_{\bar{V}_{1}^{C}}^{\infty} \Pi(V) I_{1} d V_{0}
\end{aligned}
$$

If $N P V_{0}^{C}>0$ the venture capitalist will provide funding.

\subsubsection{Debt financing with date-1 syndication.}

Date-2: At $t=1$ a syndicate of investors provides $I_{1}$, purchasing a pari passu debt issuance on competitive terms. Denoting this debt level as $K_{1}^{S}$, and defining $K$ as the total debt due or $K=K_{0}^{C}+K_{1}^{S}$, final payouts are

$$
\begin{gathered}
N P V_{2}^{M}=\max \left(0, f_{0} f_{1} V_{2}-K\right) \\
N P V_{2}^{C}=\frac{K_{0}^{C}}{K} f_{0} f_{1} V_{2}-\max \left(0, \frac{K_{0}^{C}}{K} f_{0} f_{1} V_{2}-K_{0}^{C}\right) \\
N P V_{2}^{S}=\frac{K_{1}^{S}}{K} f_{0} f_{1} V_{2}-\max \left(0, \frac{K_{1}^{S}}{K} f_{0} f_{1} V_{2}-K_{1}^{S}\right)
\end{gathered}
$$

Let $\bar{V}_{2}^{S}$ identify the point at which the entrepreneur begins receiving cash flows or

$$
\bar{V}_{2}^{S}=\frac{K}{f_{0} f_{1}}
$$




\section{Date-1:}

At date 1 , for a given combined debt level $K$, the entrepreneur's NPV and maximization problem are the same as before. We obtain $x_{1}^{\star}(K), f_{1}^{\star}(K), g_{1}^{\star}(K)$, and $N P V_{1}^{M}(K)$ from Eq. (75), but using $K=K_{0}^{C}+K_{1}^{S}$ rather than $K_{1}^{\star}$.

The face value of debt issued to the outside syndicate is determined by setting $N P V_{1}^{S}$ equal to zero. Taking the expectation of his $t=2$ payouts from (82) and using change of variables yields

$$
N P V_{1}^{S}\left(K_{1}^{S}\right)=\frac{K_{1}^{S}}{K} f_{0} f_{1} V_{1}\left(1-N_{(0,1)}\left(\phi+\frac{1}{2} \sigma\right)\right)+K_{1}^{S} N_{(0,1)}\left(\phi-\frac{1}{2} \sigma\right)-I_{1}
$$

where $\phi=\frac{1}{\sigma} \ln \frac{V_{1}}{\bar{V}_{2}^{S}}$. This implies

$$
I_{1}=\frac{K_{1}^{S}}{K} f_{0} f_{1} V_{1}\left(1-N_{(0,1)}\left(\phi+\frac{1}{2} \sigma\right)\right)+K_{1}^{S} N_{(0,1)}\left(\phi-\frac{1}{2} \sigma\right)
$$

Substituting $f_{1}^{\star}(K)$ from the entrepreneur's maximization, this is solved numerically for $K_{1}^{S}$.

We solve for $\bar{V}_{1}$ using the same procedure as in the monopolistic venture capitalist scenario, finding the point where the maximum value to the syndicate is zero. There are two differences in the syndicate's and monopolistic venture capitalist's maximization problem, both stemming from the incumbent venture capitalist's outstanding debt level. First, the debt default point, $\bar{V}_{2}^{S}$, is higher by $K_{0}^{C}$. Second, the presence of $\frac{K_{1}^{S}}{K}$, the syndicate's share of total debt, reduces the syndicate's share of firm value when debt defaults. Both imply a higher $\bar{V}_{1}^{S}$ than in the monopolistic venture capitalist scenario. Investment at date 1 occurs for $V_{1}>\bar{V}_{1}^{S}$.

\section{Date-0:}

At date 0 , the venture capitalist decides his debt level $K_{0}^{C *}$ and the entrepreneur decides how much effort to exert. For a given $K_{0}^{C}$, the entrepreneur's value is

$$
N P V_{0}^{M}\left(K_{0}^{C}\right)=\max \left[0, \max _{x_{0}}\left(E_{0} N P V_{1}^{M}\left(x_{0}\left(K_{0}^{C}\right), K_{0}^{C}\right)-g_{0}\left(x_{0}\left(K_{0}^{C}\right)\right)\right]\right.
$$

where

$$
\begin{aligned}
E_{0} N P V_{1}^{M}\left(x_{0}\left(K_{0}^{C}\right), K_{0}^{C}\right)= & f_{0} \int_{\bar{V}_{1}^{S}}^{\infty} \Pi(V) f_{1}^{\star} V N_{(0,1)}\left(\phi+\frac{1}{2} \sigma\right) d V \\
& -\int_{\bar{V}_{1}^{S}}^{\infty} \Pi(V) K N_{(0,1)}\left(\phi-\frac{1}{2} \sigma\right) d V-\int_{\bar{V}_{1}^{S}}^{\infty} \Pi(V) g_{1}^{*} d V
\end{aligned}
$$

Each $V_{1}$ realization implies $K\left(V_{1}\right), f_{1}^{\star}\left(K\left(V_{1}\right)\right)$, and $\phi\left(\bar{V}_{2}\left(K, f_{1}^{\star}\right)\right)$. We solve for $x_{0}^{\star}\left(K_{0}^{C}\right)$ numerically, exactly as in the monopolistic venture capitalist case, but using the combined debt level $K=K_{0}^{C}+K_{1}^{S}$.

The venture capitalist anticipates $x_{0}^{\star}\left(K_{0}^{C}\right)$ when he sets $K_{0}^{C}$. He restricts his search to $K_{0}^{C} \in\left(0, K_{0}^{C}(\max )\right]$, where $K_{0}^{C}(\max )$ is such that

$$
E_{0} N P V_{1}^{M}\left(x_{0}^{\star}\left(K_{0}^{C}(\max )\right), K_{0}^{C}(\max )\right)-g_{0}\left(x_{0}^{\star}\left(K_{0}^{C}(\max )\right)\right)=0
$$


This constraint rarely binds, and $K_{0}^{C *}$ is chosen to maximize

$$
N P V_{0}^{C}=\max \left[0, \max _{K_{0}^{C}(\max ) \geq K_{0}^{C}} E_{0} N P V_{1}^{C}\left(x_{0}^{\star}\left(K_{0}^{C}\right), K_{0}^{C}\right)-I_{0}\right]
$$

Using $x_{0}^{\star}$ from the entrepreneur's maximization, the venture capitalist's expected $t=1$ value is

$$
\begin{aligned}
E_{0} N P V_{1}^{C}\left(x_{0}^{\star}\left(K_{0}^{C}\right), K_{0}^{C}\right)= & K_{0}^{C} f_{0} \int_{\bar{V}_{1}^{S}}^{\infty} \Pi(V) f_{1}^{\star} \frac{V}{K}\left(1-N_{(0,1)}\left(\phi+\frac{1}{2} \sigma\right)\right) d V \\
& +K_{0}^{C} \int_{\bar{V}_{1}^{S}}^{\infty} \Pi(V) N_{(0,1)}\left(\phi-\frac{1}{2} \sigma\right) d V
\end{aligned}
$$

We solve for $K_{0}^{C *}$ numerically, again evaluating the integrals point-by-point, ending the summation at 6 standard deviations of $V_{1}$. If $N P V_{0}^{C} \geq 0$ investment will proceed. 


\section{References}

[1] Admati, A.R. and P. Pfleiderer, 1994, "Robust Financial Contracting and the Role of Venture Capitalists", Journal of Finance, 371-402.

[2] Aghion, P. and P. Bolton, 1992, "An Incomplete Contract Approach to Financial Contracting," Review of Economic Studies, 59, 473-494.

[3] Aghion, P., Bolton, P. and J. Tirole, 2004, "Exit Options in Corporate Finance: Liquidity versus Incentives", Review of Finance, forthcoming.

[4] Bergemann and Hege, 1998, "Venture Capital Finance, Moral Hazard and Learning", Journal of Banking and Finance, 22, 703-735.

[5] Berglöf, E. 1994, "A Control Theory of Venture Capital Finance", Journal of Law, Economics and Organization, 10, 247-267.

[6] Bhattacharya, S. and A. Faure-Grimaud, 2001, "The Debt Hangover: Renegotiation with Noncontractible Investment," Economics Letters, 70, 413-419.

[7] Black, B. and R. Gilson, 1998, "Venture Capital and the Structure of Capital Markets", Journal of Financial Economics, 47, 243-277.

[8] Boyd, J. and B. Smith, 1994, How Good Are Standard Debt Contracts? Stochastic Versus Non-stochastic Monitoring in a Costly State Verification Environment, Journal of Business, 67, 539-561.

[9] Cestone, G. and L. White, 2003, "Anticompetitive Financial Contracting: The Design of Financial Claims", Journal of Finance, 58, 2109-2141.

[10] Cassamatta, C., 2003, Financing and Advising: Optimal Financial Contracts with Venture Capitalists, Journal of Finance, 58, 2059-2086.

[11] Cassamatta, C. and C. Haritchabalet, 2004, Learning and Syndication in Venture Capital Investments, mimeo, University of Toulouse.

[12] Chemla, G., Habib, M. and A. Lyngquist, 2002, Shareholder Agreements, Working Paper, University of British Columbia.

[13] Cornelli, F. and O. Yosha, 2003, "Stage Financing and the Role of Convertible Securities", Review of Economic Studies, 70, 1-32.

[14] Fenn, G., W. Liang and S. Prowse, 1995, "The Economics of the Private Equity Market", Boards of Governors of the Federal Reserve System Publications.

[15] Fluck, Z., 1998, "Optimal Financial Contracting: Debt versus Outside Equity," Review of Financial Studies, 11, 383-418.

[16] Fluck, Z., 2001, Financial Contracting in Start-ups and Ongoing Firms: A Life-cycle Theory of Financing, Working Paper, Michigan State University. 
[17] Gompers, 1995, "Optimal Investment, Monitoring and the Staging of Venture Capital", Journal of Finance, 50, 1461-1489.

[18] Gompers, Paul A., and J. Lerner, 1996, "The Use of Covenants: An Empirical Analysis of Venture Partnership Agreements". Journal of Law and Economics, 39, No. 2, 463-498.

[19] Gompers, P. and J. Lerner, 2002, The Venture Capital Cycle, MIT Press, Cambridge, MA.

[20] Gompers, P., Lerner, J. and D. Scharfstein, 2003, Entrepreneurial Spawning: Public Corporations and the Genesis of New Ventures, 1986-1999, Working Paper, Harvard University.

[21] Gorman, A. and W. Sahlman, 1989, "What do Venture Capitalists Do?", Journal of Business Venturing, 4, 231-248.

[22] Green, R., 1984, "Investment Incentives, Debt and Warrants", Journal of Financial Economics, 13, 115-136.

[23] Gromb, D. and D. Scharfstein, 2003, Entrepreneurship in Equilibrium, Working Paper, MIT.

[24] Hellmann, T., 1998, "The allocation of control rights in venture capital contracts", Rand Journal of Economics, 29, 57-76.

[25] Hellmann, T. and M. Puri, 2000, "The Interaction of Product market and Financing Strategy: The Role of Venture Capital", Review of Financial Studies, 13, 959-984.

[26] Hellmann, T. and M. Puri, 2002, "Venture Capital and the Professionalization of Startup Firms: Empirical Evidence", Journal of Finance, 57, 169-197.

[27] Inderst and Mueller, 2003, Venture Capital Contracts and Market Structure, Working Paper, New York University.

[28] Kalay, A. and J. Zender, 1997, "Bankruptcy, Warrants, and State-Contingent Changes in the Ownership of Control", Journal of Financial Intermediation, 6(4), 347-379.

[29] Kaplan, S. and Strömberg, 2003, "Financial Contracting Theory Meets the Real World: An Empirical Analysis of Venture Capital Contracts", Review of Economic Studies, 70, 281-315.

[30] Landier, 2001, Start-Up Financing: From Banks to Venture Capital, Working Paper, MIT.

[31] Landier and Thesmar, 2003, Entrepreneurial Optimism and Financial Contracting, Working Paper, New York University.

[32] Leland, H., 1994, "Corporate Debt Value, Bond Covenants, and Optimal Capital Structure", Journal of Finance, 49, 1213-1252.

[33] Leland, H., 1998, "Agency Costs, Risk Management and Capital Structure", Journal of Finance, 53, 1213-1244. 
[34] Lerner, J., 1994, "The Syndication of Venture Capital Investments", Financial Management, Vol. 23 (Autumn), 16-27.

[35] Mello and Parsons, 1992, "Measuring the Agency Cost of Debt", Journal of Finance, 47, 1887-1904.

[36] Myers, S., 1977, "The Determinants of Corporate Borrowing," Journal of Financial Economics, 147-176.

[37] Myers, S., 1984, "The Capital Structure Puzzle," Journal of Finance, 39, 575-592.

[38] Myers, S. and N. Majluf, 1984, "Financing Decisions When Firms Have Information that Investors Do Not Have," Journal of Financial Economics, 13, 187-221.

[39] Myers, S. C., 2000, "Outside Equity", Journal of Finance , 55, 1005-1038.

[40] Neher, D., 1999, "Staged Financing: An Agency Perspective", Review of Economic Studies, 66, 255-275.

[41] Ju, N., Parrino, R., Poteshman, A. and M. Weisbach, 2004, "Horses or Rabbits? Tradeoff Theory and Optimal Capital Structure", Journal of Financial and Quantitative Analysis, forthcoming.

[42] Nöldeke, G. and K. Schmidt, 1998, "Sequential Investments and Options to Own", Rand Journal of Economics, 29, 633-653.

[43] Parrino, R. and M. Weisbach, 1999, "Measuring Investment Distortions Arising from the Stockholder-Bondholder Conflict", Journal of Financial Economics, 53, 3-42.

[44] Parrino, R., Poteshman, A. and M. Weisbach, 2002, "Measuring Investment Distortions When Risk-Averse Managers Decide Whether to Undertake Risky Projects", Working Paper, University of Illinois.

[45] Petersen and Rajan, 1994, "The Effect of Credit Market Competition on Lending Relationships", Quarterly Journal of Economics, 110, 407-443.

[46] Pichler, P. and W. Wilhelm, 2001, "A Theory of the Syndicate: Form Follows Function", Journal of Finance, 56(6), 2237-64.

[47] Rajan R., 1992, "Insiders and Outsiders: The Choice between Informed and Arm's Length Debt", Journal of Finance, 47(4), 1367-1400.

[48] Repullo, R. and J. Suarez, 2004, "Venture Capital Finance: A Security Design Approach", Review of Finance, 8, 75-108.

[49] Robe, M., 1999, "Optimal versus Traditional Securities under Moral Hazard", Journal of Financial and Quantitative Analysis, 34, 161-189.

[50] Robe, M., 2001, "What can we learn from simulating a standard agency model?", Economics Letters, 73, 137-146. 
[51] Sah and Stiglitz, 1986, "The Architecture of Economic Systems: Hierarchies and Polyarchies", American Economic Review (September), 716-727.

[52] Sahlman, W. A., 1990, "The Structure and Governance of Venture Capital Organizations", Journal of Financial Economics (October), 473-521.

[53] Schmidt, K., 2003, "Convertible Securities and Venture Capital Finance", Journal of Finance, 58(3), 1139-1166.

[54] Wilson, R., 1968, "The Theory of Syndicates", Econometrica (January), 119-132.

[55] Winton, A. and V. Yerramilli, 2003, A Model of Entrepreneurial Finance, Working Paper, University of Minnesota. 


\section{$9 \quad$ Tables and Figures}

Table 1. Example of numerical results for nine cases: (1) No cost of effort (Black-Scholes), (2) First-best, (3) Monopoly (one investor provides all financing), (4) 100\% Upfront financing, (5) Syndicate Financing at date 1, (6) Fully Competitive financing at dates 0 and 1, (7) Monopoly Debt Financing (investor sets date 1 debt level instead of equity share), (8) Syndicate Debt Financing at date 1 (initial investor sets debt level and syndicate sets paripassu debt level at date 1) and (9) Fully Competitive Debt Financing at dates 0 and 1. The entrepreneur's initial ownership share or contracted debt level, where relevant, is $\alpha_{0}^{M}$ and $K_{0}$ and effort is $x_{0} . \bar{V}$ is the minimum value necessary for investment at date $1 . \mathrm{NPV}$ is the net present value at date 0 , overall and for the entrepreneur (M) and initial investor (C). Potential value is $V_{0}=E_{0}\left(V_{2}\right)=150 . I_{0}$ and $I_{1}$ denote fixed investment costs, and $\sigma$ is standard deviation per period of $V_{t}$. Effort parameters are $\theta_{f}$ (value-added) and $\theta_{g}$ (cost). Increases in $\theta_{f}$ and $\theta_{g}$ represent increases in marginal returns and costs to effort, respectively.

A. $I_{0}=50, I_{1}=50, \sigma=0.4, \theta_{f}=1.8, \theta_{g}=0.6$

Black-Scholes

First-best

Monopoly

Monopoly, No Staging

Syndicate, date 1

Competitive, dates 0, 1

Monopoly (Debt)

Syndicate, date 1 (Debt)

Competitive, dates 0, 1 (Debt)

\begin{tabular}{rrrrrrr}
$\alpha_{0}^{M}$ & $K_{0}$ & $x_{0}$ & $\bar{V}$ & $N P V^{M}$ & $N P V^{C}$ & $N P V$ \\
\hline- & - & $\infty$ & 50.00 & - & - & 50.03 \\
1.00 & - & 2.54 & 55.35 & 37.90 & - & 37.90 \\
- & - & 1.18 & 70.84 & 3.43 & 13.58 & 17.01 \\
0.09 & - & 1.54 & 23.77 & 7.53 & 19.36 & 26.89 \\
0.15 & - & 1.72 & 84.93 & 7.05 & 20.50 & 27.55 \\
0.46 & - & 2.22 & 69.10 & 36.02 & 0.00 & 36.02 \\
- & - & 0.00 & $\infty$ & $-1.00^{*}$ & $-50.00^{*}$ & $-51.00^{*}$ \\
- & 109.31 & 2.27 & 124.60 & 17.80 & 3.92 & 21.72 \\
- & 76.69 & 2.39 & 105.48 & 30.47 & 0.00 & 30.47
\end{tabular}

B. $I_{0}=50, I_{1}=50, \sigma=0.8, \theta_{f}=1.8, \theta_{g}=0.6$

Black-Scholes

First-best

Monopoly

Monopoly, No Staging

Syndicate, date 1

Competitive, dates 0, 1

Monopoly (Debt)

Syndicate, date 1 (Debt)

Competitive, dates 0, 1 (Debt)

\begin{tabular}{rrrrrrr}
$\alpha_{0}^{M}$ & $K_{0}$ & $x_{0}$ & $\bar{V}$ & $N P V^{M}$ & $N P V^{C}$ & $N P V$ \\
\hline- & - & $\infty$ & 50.00 & - & - & 52.55 \\
1.00 & - & 2.52 & 55.37 & 41.48 & - & 41.48 \\
- & - & 1.17 & 71.14 & 2.59 & 19.45 & 22.05 \\
0.10 & - & 1.55 & 22.97 & 8.11 & 19.42 & 27.53 \\
0.13 & - & 1.64 & 87.28 & 7.00 & 23.95 & 30.95 \\
0.48 & - & 2.21 & 68.83 & 39.63 & 0.00 & 39.63 \\
- & - & 2.02 & 60.22 & 8.15 & 31.40 & 39.55 \\
- & 355.84 & 2.08 & 143.77 & 16.15 & 7.66 & 23.80 \\
- & 167.75 & 2.29 & 103.12 & 34.85 & 0.00 & 34.85
\end{tabular}

*indicates projects that yield, at best, negative net present value to at least one party. Such projects will not be implemented. 
C. $I_{0}=10, I_{1}=90, \sigma=0.4, \theta_{f}=1.8, \theta_{g}=0.6$

Black-Scholes

First-best

Monopoly

Monopoly, No Staging

Syndicate, date 1

Competitive, dates 0, 1

Monopoly (Debt)

Syndicate, date 1 (Debt)

Competitive, dates 0, 1 (Debt)

\begin{tabular}{rrrrrrr}
$\alpha_{0}^{M}$ & $K_{0}$ & $x_{0}$ & $\bar{V}$ & $N P V^{M}$ & $N P V^{C}$ & $N P V$ \\
\hline- & - & $\infty$ & 90.00 & - & - & 52.19 \\
1.00 & - & 2.50 & 96.56 & 40.98 & - & 40.98 \\
- & - & 1.35 & 117.44 & 2.16 & 24.55 & 26.71 \\
0.09 & - & 1.54 & 23.77 & 7.53 & 19.36 & 26.89 \\
0.21 & - & 1.80 & 130.60 & 5.15 & 26.34 & 31.49 \\
0.82 & - & 2.42 & 110.15 & 39.44 & 0.00 & 39.44 \\
- & - & 0.00 & $\infty$ & $-1.00^{*}$ & $-10.00^{*}$ & $-11.00^{*}$ \\
- & 91.18 & 2.15 & 154.65 & 10.39 & 18.52 & 28.92 \\
- & 15.00 & 2.46 & 108.72 & 40.34 & 0.00 & 40.34
\end{tabular}

D. $I_{0}=10, I_{1}=90, \sigma=0.8, \theta_{f}=1.8, \theta_{g}=0.6$

Black-Scholes

First-best

Monopoly

Monopoly, No Staging

Syndicate, date 1

Competitive, dates 0, 1

Monopoly (Debt)

Syndicate, date 1 (Debt)

Competitive, dates 0, 1 (Debt)

\begin{tabular}{crrrrrr}
$\alpha_{0}^{M}$ & $K_{0}$ & $x_{0}$ & $\bar{V}$ & $N P V^{M}$ & $N P V^{C}$ & $N P V$ \\
\hline- & - & $\infty$ & 90.00 & - & - & 64.09
\end{tabular}

$\begin{array}{lllllll}1.00 & - & 2.46 & 96.63 & 54.44 & - & 54.44\end{array}$

$\begin{array}{lllllll}- & - & 1.18 & 121.54 & 1.59 & 37.29 & 38.87\end{array}$

$\begin{array}{lllllll}0.10 & - & 1.55 & 22.97 & 8.11 & 19.42 & 27.53\end{array}$

$\begin{array}{lllllll}0.15 & - & 1.63 & 138.44 & 5.35 & 40.20 & 45.55\end{array}$

$\begin{array}{lllllll}0.86 & - & 2.40 & 109.85 & 53.59 & 0.00 & 53.59\end{array}$

$\begin{array}{lllllll}- & - & 1.97 & 106.86 & 6.87 & 45.87 & 52.74\end{array}$

$\begin{array}{lllllll}- & 422.88 & 1.94 & 204.69 & 9.61 & 29.09 & 38.71\end{array}$

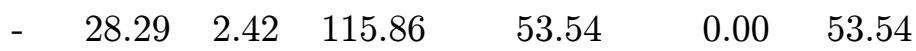

*indicates projects that yield, at best, negative net present value to at least one party. Such projects will not be implemented. 
E. $I_{0}=10, I_{1}=90, \sigma=0.4, \theta_{f}=0.6, \theta_{g}=0.6$

Black-Scholes

First-best

Monopoly

Monopoly, No Staging

Syndicate, date 1

Competitive, dates 0,1

Monopoly (Debt)

Syndicate, date 1 (Debt)

Competitive, dates 0, 1 (Debt)

\begin{tabular}{rrrrrrr}
$\alpha_{0}^{M}$ & $K_{0}$ & $x_{0}$ & $\bar{V}$ & $N P V^{M}$ & $N P V^{C}$ & $N P V$ \\
\hline- & - & $\infty$ & 90.00 & - & - & 52.19 \\
1.00 & - & 3.88 & 123.11 & 10.98 & - & 10.98 \\
- & - & 2.15 & 187.29 & $-0.94^{*}$ & $-3.19^{*}$ & $-4.13^{*}$ \\
0.22 & - & 2.72 & 23.14 & 10.85 & $-23.55^{*}$ & $-12.70^{*}$ \\
0.51 & - & 3.05 & 178.85 & 1.98 & $-0.43^{*}$ & 1.55 \\
0.51 & - & 3.05 & 178.85 & 1.98 & - & 1.55 \\
- & - & 0.00 & $\infty$ & $-1.00^{*}$ & $-10.00^{*}$ & $-11.00^{*}$ \\
- & 47.39 & 3.30 & 177.18 & 3.14 & 1.17 & 4.31 \\
- & 30.34 & 3.54 & 158.73 & 7.53 & 0.00 & 7.53
\end{tabular}

F. $I_{0}=10, I_{1}=90, \sigma=0.8, \theta_{f}=0.6, \theta_{g}=0.6$

Black-Scholes

First-best

Monopoly

Monopoly, No Staging

Syndicate, date 1

Competitive, dates 0, 1

Monopoly (Debt)

Syndicate, date 1 (Debt)

Competitive, dates 0, 1 (Debt)

\begin{tabular}{rrrrrrr}
$\alpha_{0}^{M}$ & $K_{0}$ & $x_{0}$ & $\bar{V}$ & $N P V^{M}$ & $N P V^{C}$ & $N P V$ \\
\hline- & - & $\infty$ & 90.00 & - & - & 64.09 \\
1.00 & - & 3.87 & 123.15 & 27.72 & - & 27.72 \\
- & - & 1.88 & 200.74 & 0.29 & 7.59 & 7.88 \\
0.21 & - & 2.72 & 23.29 & 11.29 & $-22.48^{*}$ & $-11.19^{*}$ \\
0.35 & - & 2.80 & 197.18 & 5.01 & 12.50 & 17.50 \\
0.79 & - & 3.63 & 158.20 & 24.95 & 0.00 & 24.95 \\
- & - & 0.00 & $\infty$ & $-1.00^{*}$ & $-10.00^{*}$ & $-11.00^{*}$ \\
- & 218.35 & 3.10 & 229.72 & 6.51 & 10.94 & 17.45 \\
- & 41.06 & 3.71 & 153.95 & 26.15 & 0.00 & 26.15
\end{tabular}

*indicates projects that yield, at best, negative net present value to at least one party. Such projects will not be implemented. 
Figure 1: Effort functions. As effort increases, the return to effort approaches 1 (100\% of potential value). The marginal cost of effort is positive and increasing. The return and cost curves depend on parameters $\theta_{f}$ and $\theta_{g}$, which are varied here between 0.2 and 2.2.
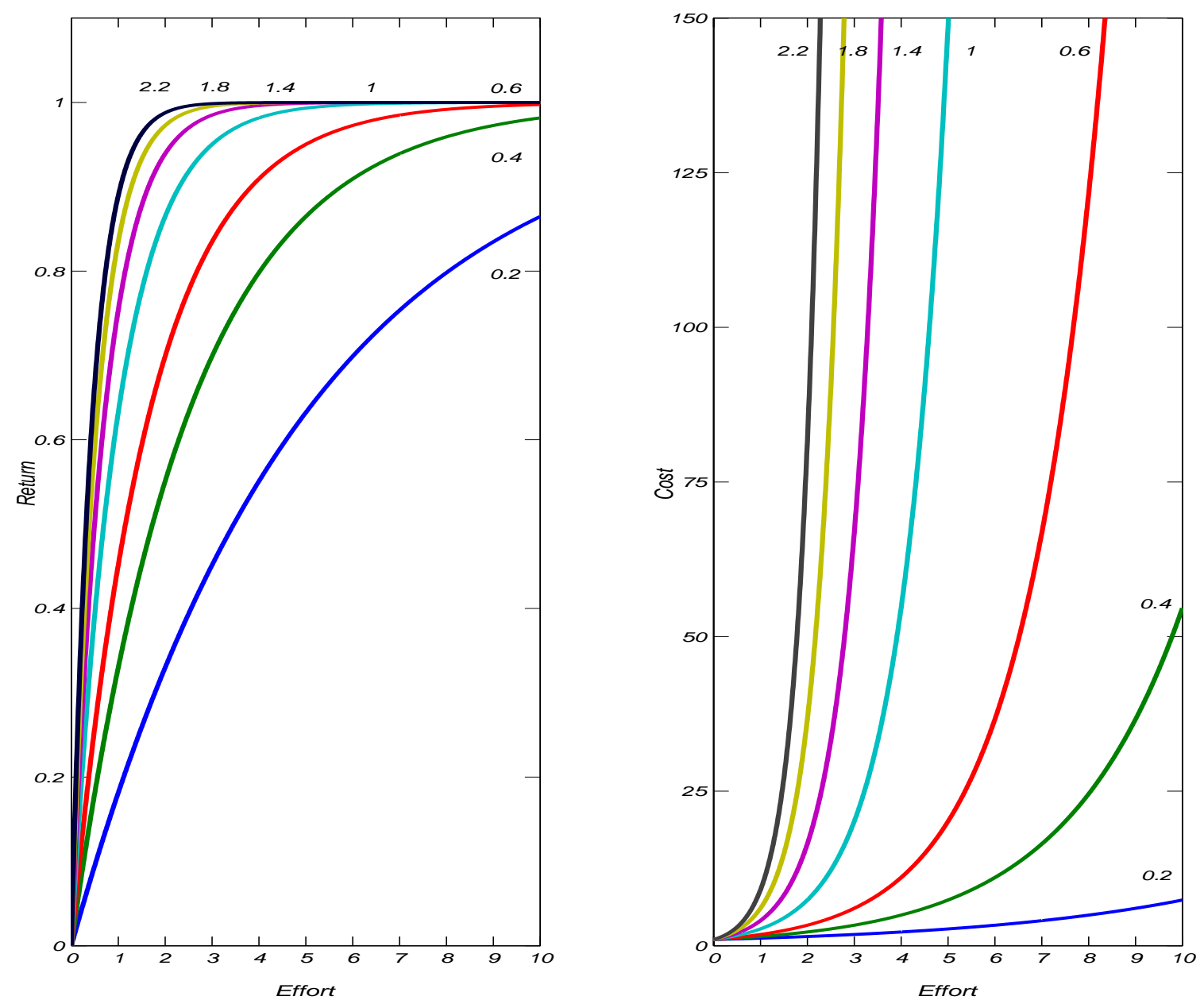
Figure 2: Date-1 Net present values are plotted against $V_{1}$, the date- 1 realization of maximum potential value. Potential value is $V_{0}=E_{0}\left(V_{2}\right)=150$. The lognormal probability density is plotted for a standard deviation of 0.4. Date-1 investment is $I_{1}=50$. With no costs of effort, $N P V_{1}=V_{1}-I_{1}$. When effort is costly, the level and slope of $N P V_{1}$ decline because of reduced effort at date 0 (the optimal effort $x_{0}^{\star}$ is too low to attain maximum potential value). The strike value $\bar{V}_{1}$, which incorporates the cost of date- 1 effort, increases from $I_{1}$ to $I_{1}+g\left(x_{1}^{\star}\right)=70.84$.

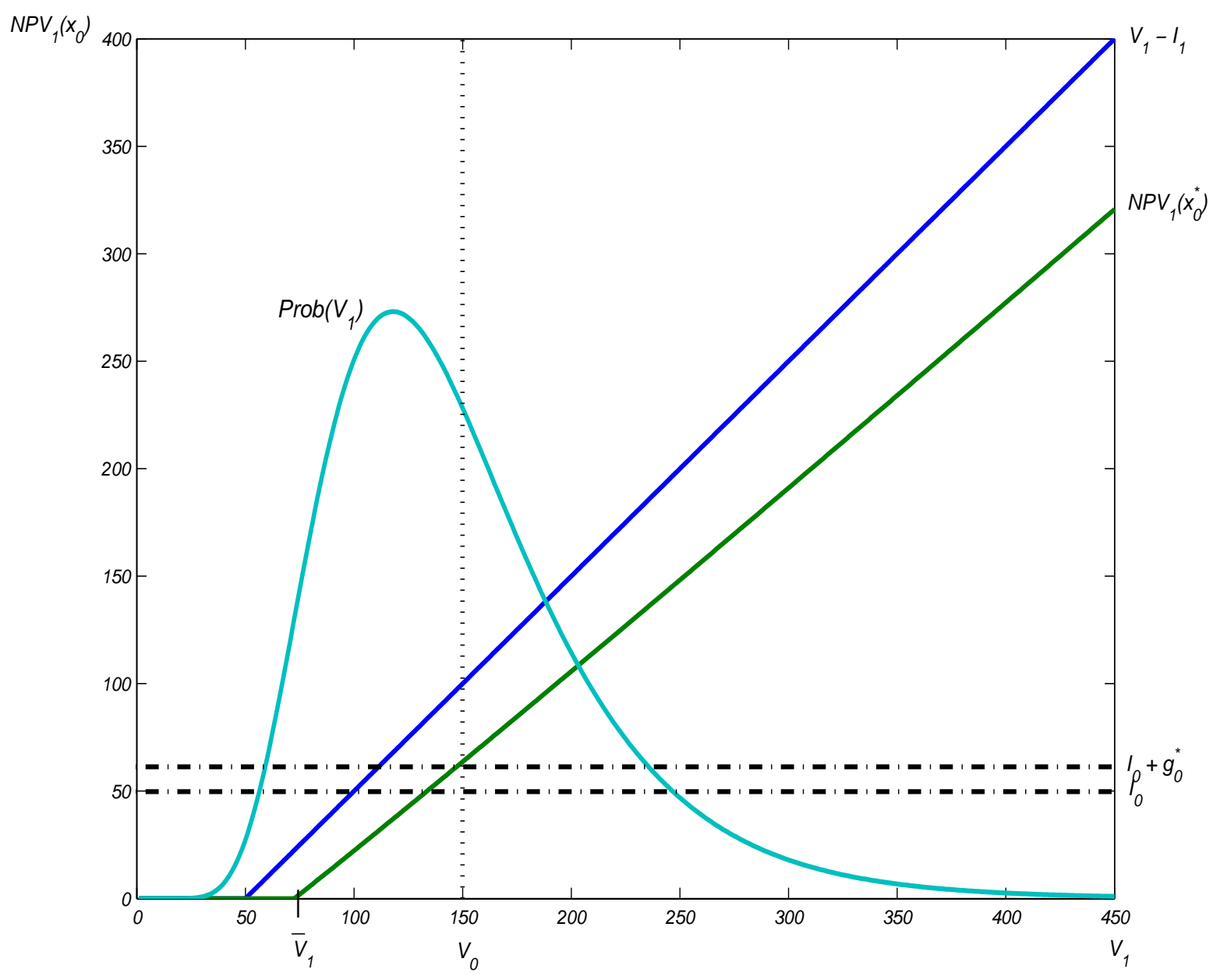


Figure 3: Net Present Value at date 0 in the first-best scenario. $N P V$ is shown across a range of standard deviation $(\sigma \in[0.1,1.2])$ and effort return $\left(\theta_{f} / \theta_{g} \in[1 / 11,11]\right)$ parameters. The dark surface presents date- 0 and date- 1 investment levels $I_{0}=I_{1}=50$ while the light surface presents $I_{0}=10, I_{1}=90$. Potential value is $V_{0}=E_{0}\left(V_{2}\right)=150$.

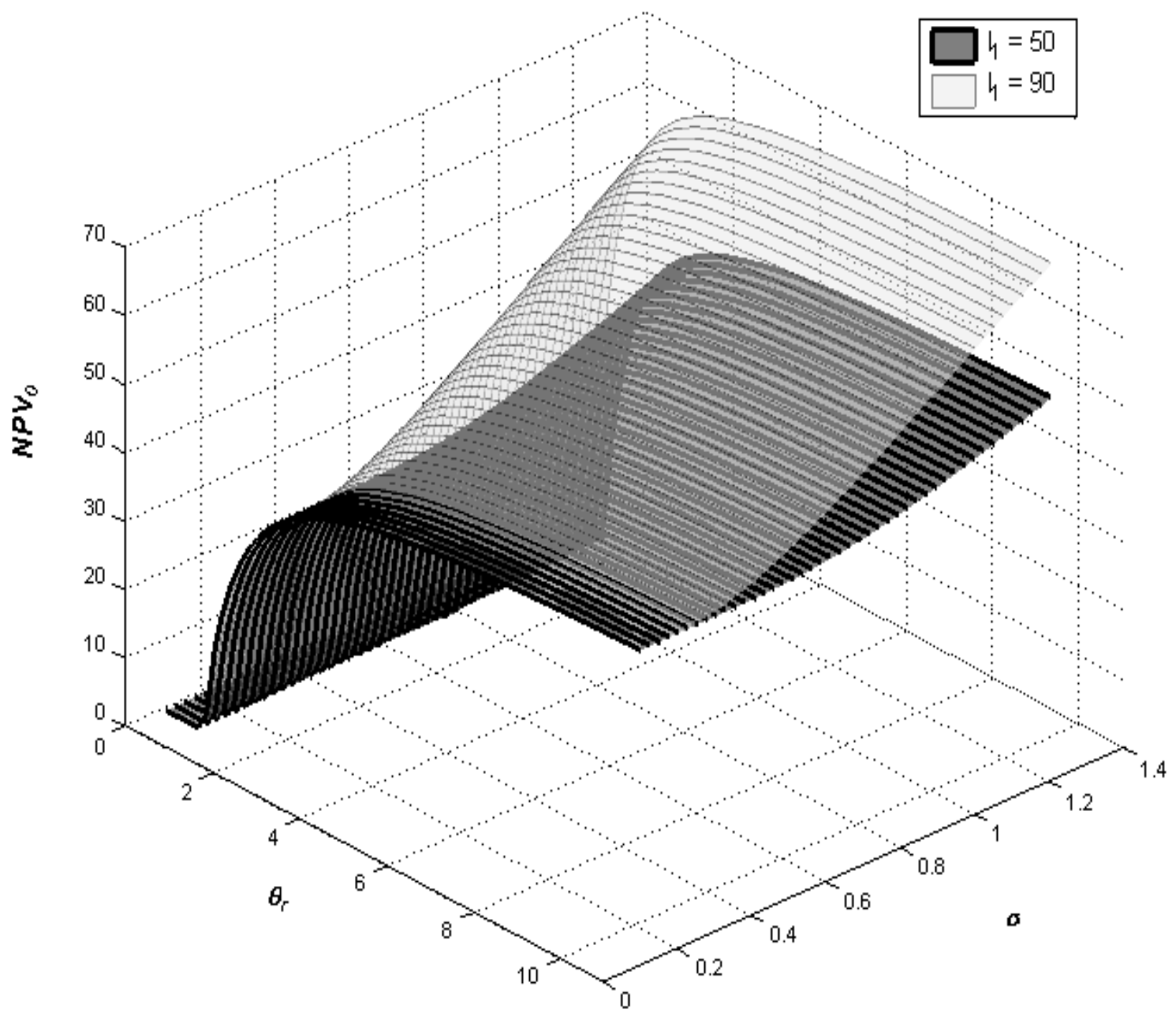


Figure 4: A typical plot of ownership shares at date 1 for the entrepreneur (M) and venture capitalist $(\mathrm{C})$ in the monopoly case in where one venture capitalist provides all stage-0 and stage-1 financing. Two curves are shown for the venture capitalist. The first $\alpha_{M A X}^{C}$ is the maximum share at which the entrepreneur will still participate. The second $\alpha_{F O C}^{C}$ is the optimal share, at which the entrepreneur is provided with positive $N P V$ and the incentive for continued effort. The optimal share is lower than the maximum share in the region where $V_{1}$ exceeds the strike value $\overline{V_{1}}$. The entrepreneur's minority share $\alpha^{M}$ declines as $V_{1}$ increases.

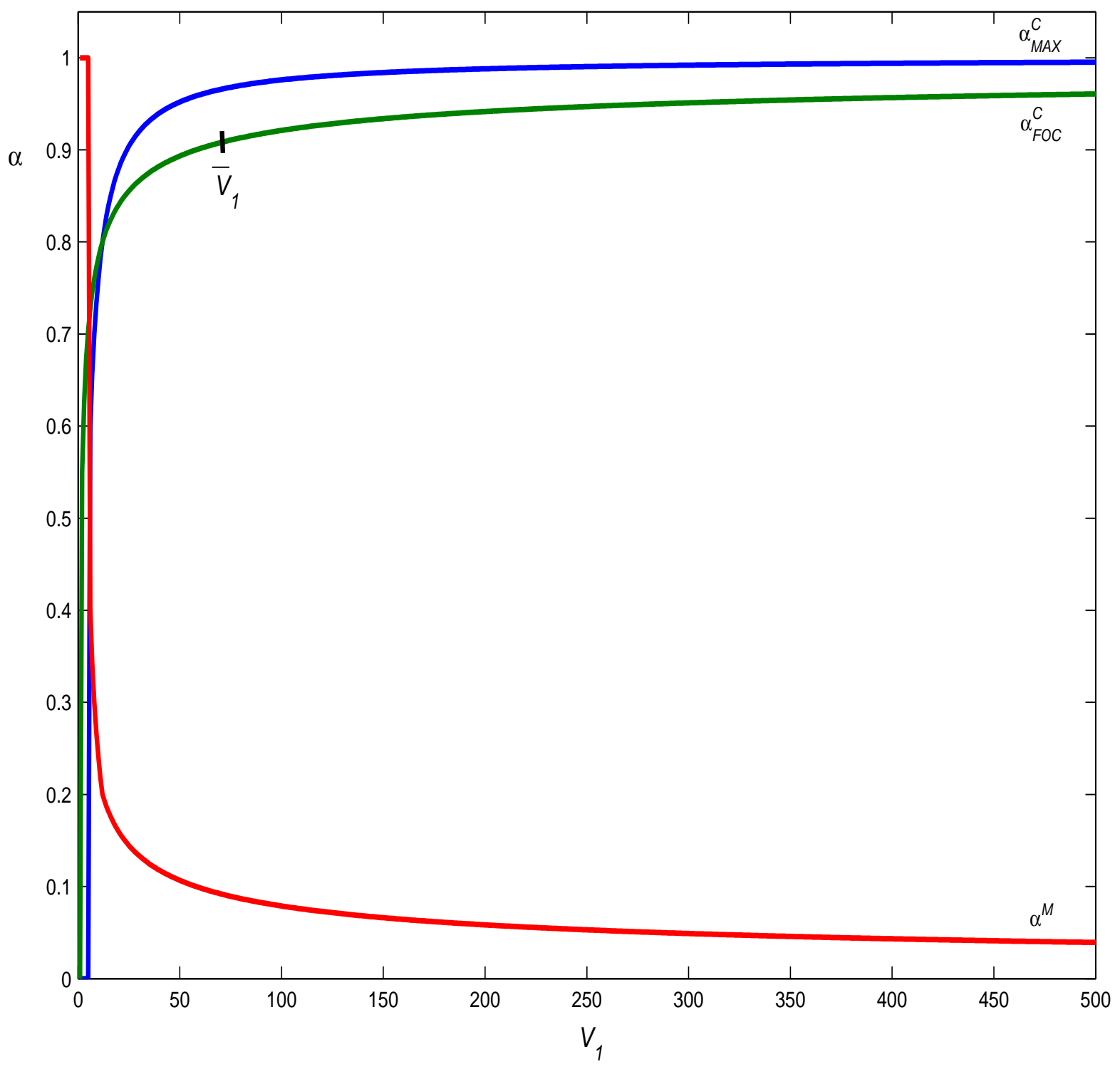


Figure 5: Net Present Value at date 0, plotted for the Monopoly and Monopoly, No Staging financing scenarios. $\quad N P V$ is shown across a range of standard deviation $(\sigma \in[0.1,1.2])$ and effort return $\left(\theta_{f} / \theta_{g} \in[1 / 11,11]\right)$ parameters. The dark surface presents non-staged $N P V$ s while the light surface presents staged $N P V \mathrm{~s}$. Figure 5 assumes date- 0 and date- 1 investment levels $I_{0}=I_{1}=50$ and potential value of $V_{0}=E_{0}\left(V_{2}\right)=150$.

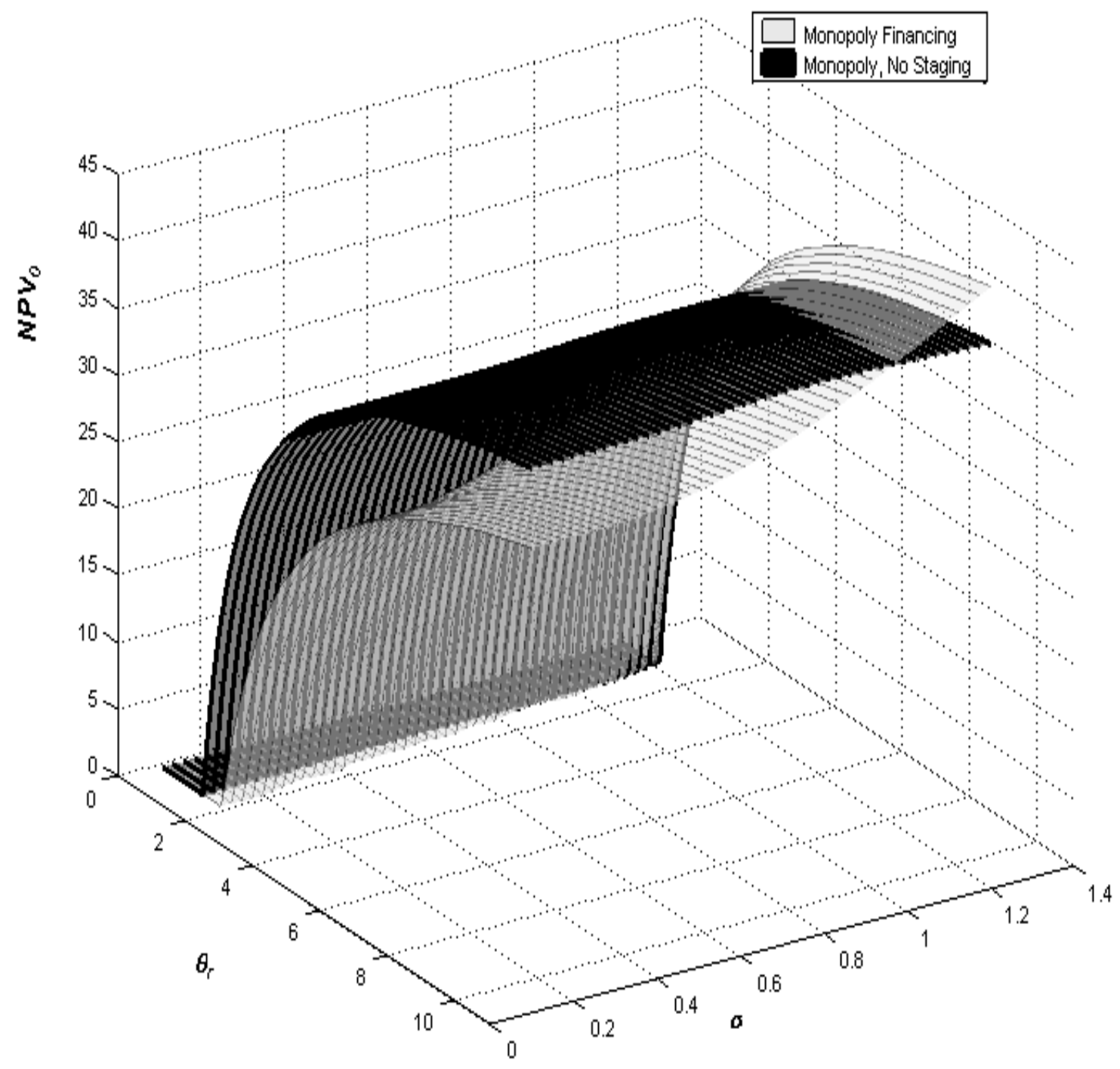


Figure 6: Net Present Value at date 0, plotted for the Monopoly and Monopoly, No Staging financing scenarios. $N P V$ is shown across a range of standard deviation $(\sigma \in[0.1,1.2])$ and effort return $\left(\theta_{f} / \theta_{g} \in[1 / 11,11]\right)$ parameters. The dark surface presents non-staged $N P V$ s while the light surface presents staged $N P V$ s. Figure 6 assumes date- 0 and date- 1 investment levels $I_{0}=10, I_{1}=90$ and potential value of $V_{0}=E_{0}\left(V_{2}\right)=150$.

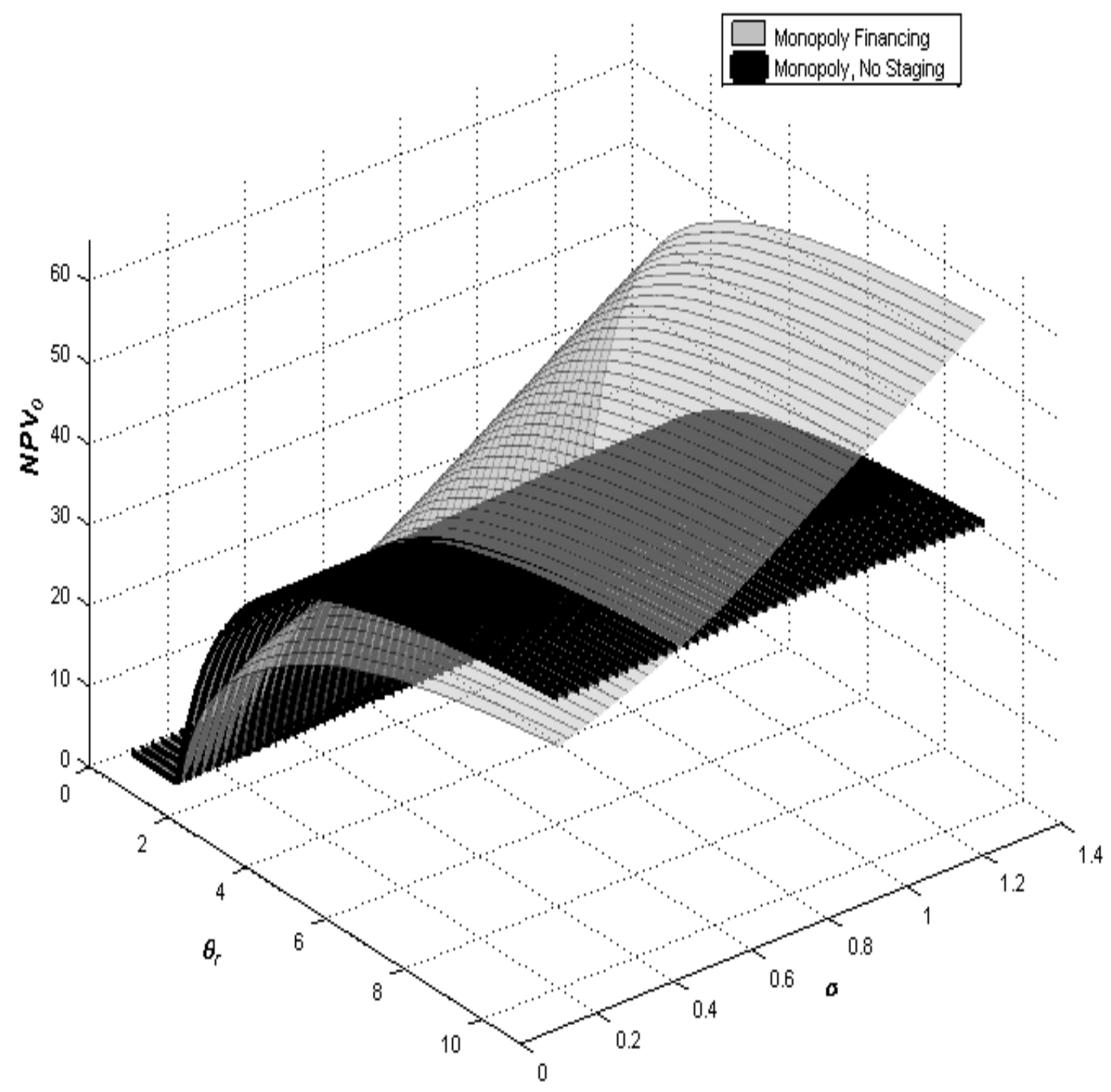


Figure 7: A typical plot of ownership shares at date 1 for the entrepreneur (M), initial venture capitalist $(\mathrm{C})$ and syndicate of new investors $(\mathrm{S})$ for the syndicate case. The syndicate provides financing on competitive terms $(N P V=0)$ whenever $V_{1}$ exceeds the strike value $\overline{V_{1}}$, which is higher than in the monopoly case shown in Figure 4. The syndicate's optimal share $\alpha_{F O C}^{S}$ is lower than the maximum share $\alpha_{M A X}^{S}$ at which the entrepreneur would still participate. The constrained share $\alpha^{S}$ declines as $V_{1}$ increases, while the ownership shares held by the entrepreneur and incumbent venture capitalist increase with $V_{1}$.

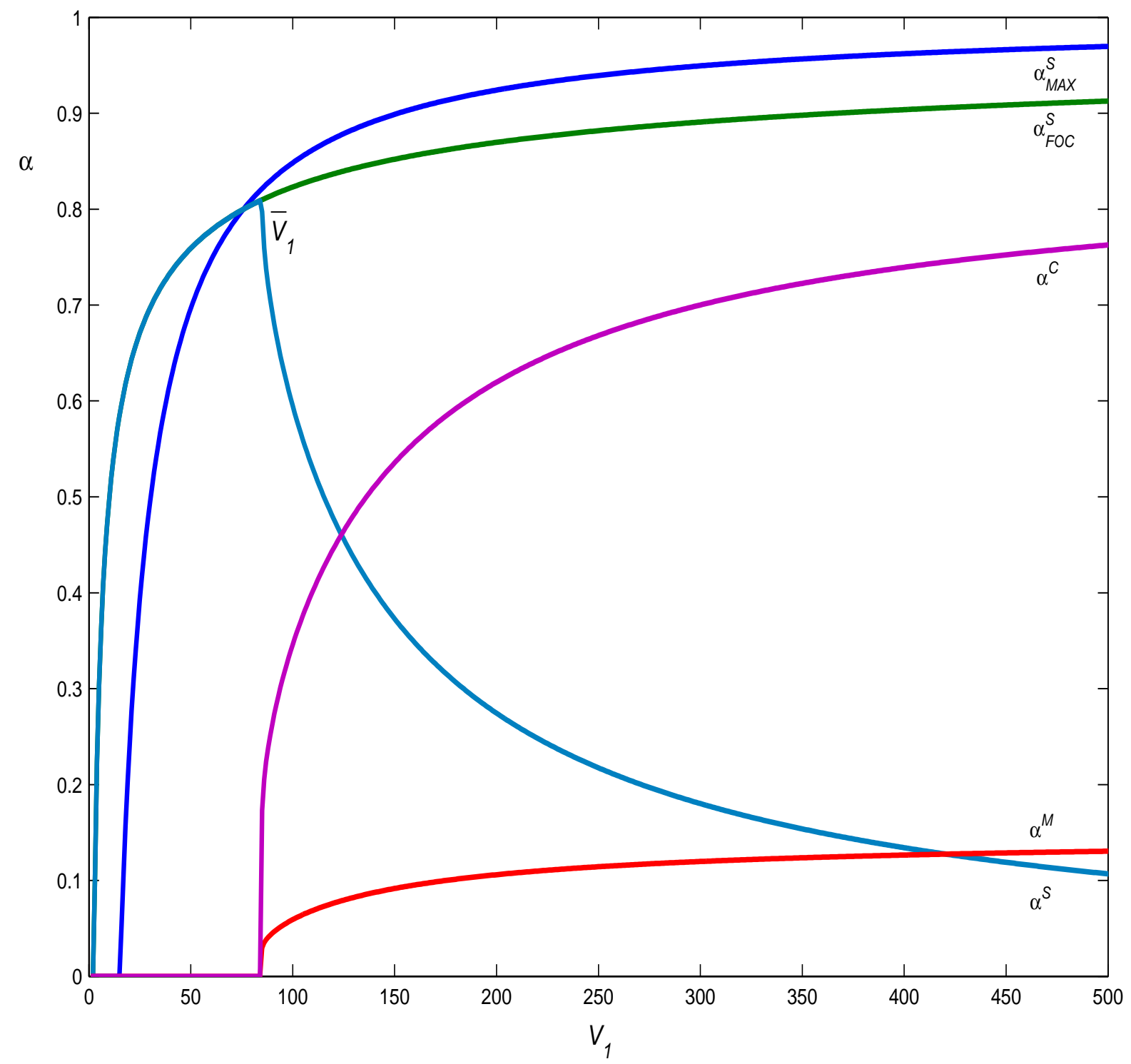


Figure 8: A typical plot of ownership shares at date 1 for the entrepreneur (M), initial syndicate (S1) and a second syndicate of new investors (S2) for the wholly competitive case. The second syndicate provides date 1 financing on competitive terms $(N P V=0)$ whenever $V_{1}$ exceeds the strike value $\overline{V_{1}}$, which is lower than in both the syndicate and monopoly cases shown previously. The constrained share $\alpha^{S 2}$ declines as $V_{1}$ increases, while the ownership shares held by the entrepreneur and incumbent investors increase with $V_{1}$. The share held by the entrepreneur $\left(\alpha^{M}\right)$ is more in parity with incumbent investors' shares, compared with the syndicate case.

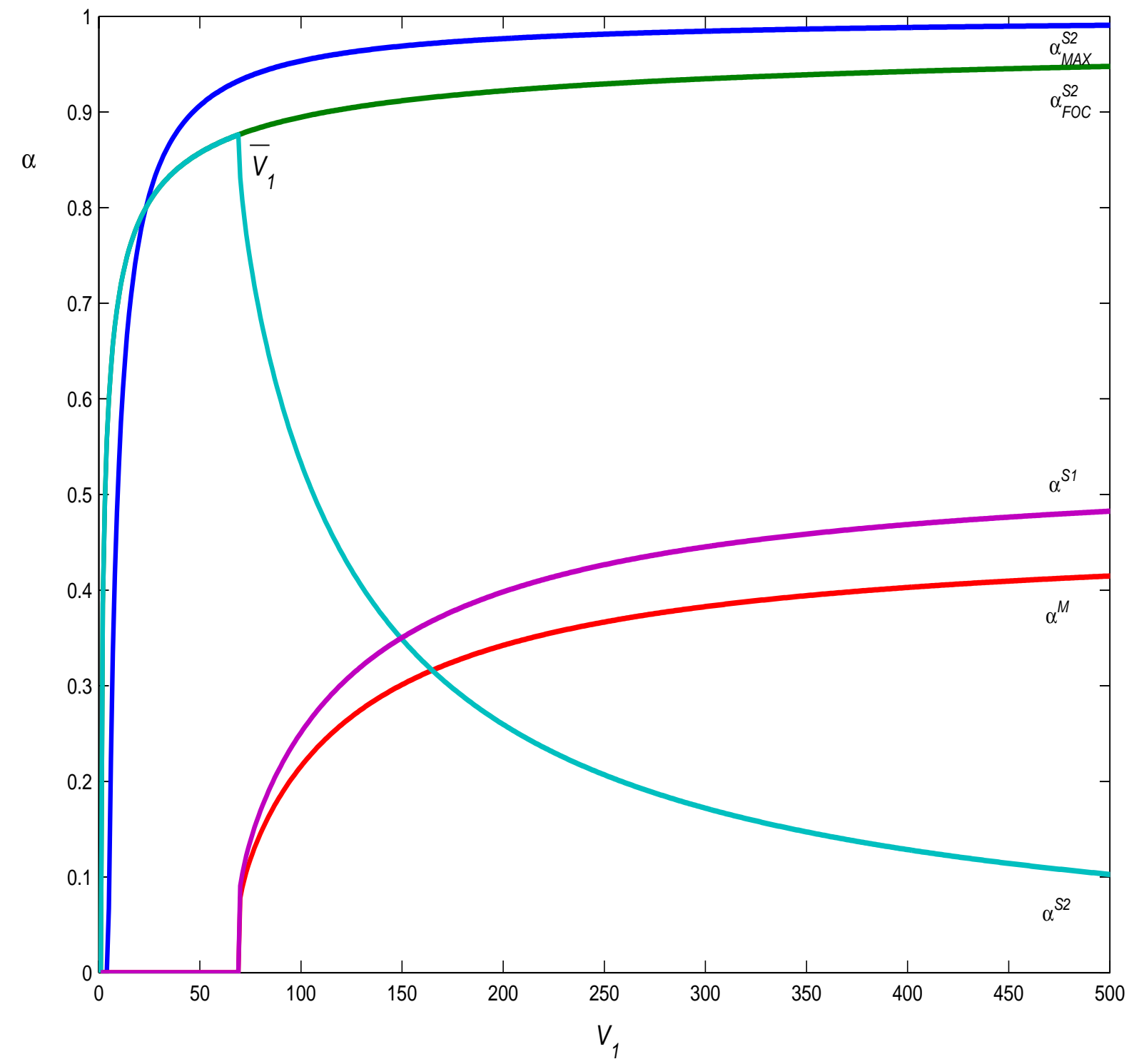


Figure 9: Net Present Value Loss at date 0, relative to first best, expressed as a percentage of total required investment. Potential value is $V_{0}=E_{0}\left(V_{2}\right)=150$. The value loss depends on the ratio of the return and cost of effort parameters, $\theta_{f} / \theta_{g}$. Lost $N P V$ is plotted for the monopoly, syndicate, and fully competitive cases, and also for the monopoly case without staging, in which the monopolist provides upfront financing and sets $\alpha_{0}^{C}$ at time 0 . Figure 9 presents 4 assumptions on date- 0 and date- 1 investments and lognormal standard deviation. In $9 \mathrm{a}$ and $9 \mathrm{~b}, I_{0}=I_{1}=50$. In $9 \mathrm{c}$ and $9 \mathrm{~d}, I_{0}=10$ and $I_{1}=90$. In $9 \mathrm{a}$ and $9 \mathrm{c}, \sigma=0.4$ while in $9 \mathrm{~b}$ and $9 \mathrm{~d}, \sigma=0.8$.

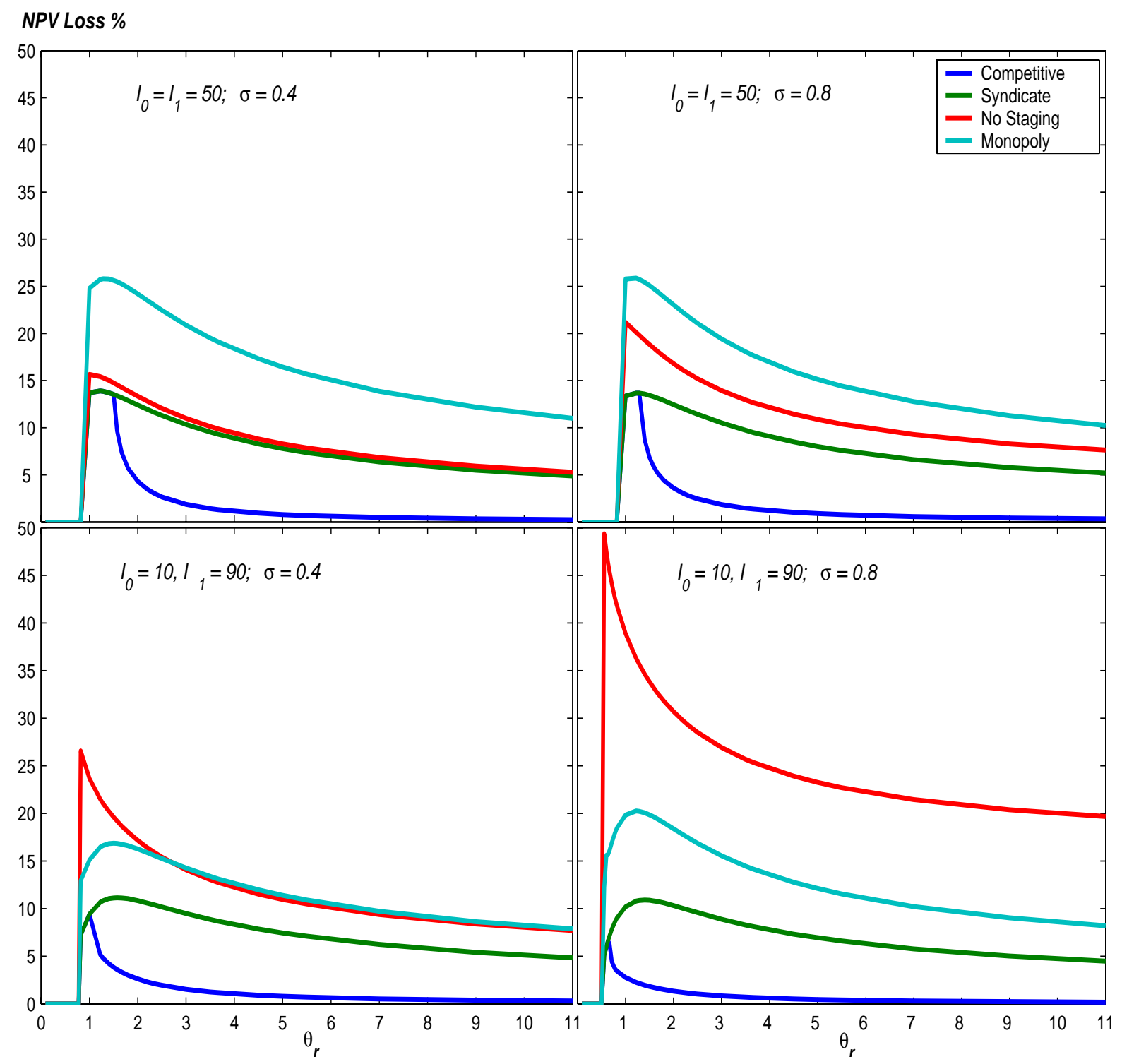


Figure 10: Net Present Value Loss at date 0, relative to first best, expressed as a percentage of total required investment. Potential value is $V_{0}=E_{0}\left(V_{2}\right)=200$. The value loss depends on the ratio of the return and cost of effort parameters, $\theta_{f} / \theta_{g}$. Lost $N P V$ is plotted for the monopoly, syndicate, and fully competitive cases, and also for the monopoly case without staging, in which the monopolist provides upfront financing and sets $\alpha_{0}^{C}$ at time 0 . Figure 10 presents 4 assumptions on date- 0 and date- 1 investments and lognormal standard deviation. In $10 \mathrm{a}$ and $10 \mathrm{~b}, I_{0}=I_{1}=50$. In $10 \mathrm{c}$ and $10 \mathrm{~d}, I_{0}=10$ and $I_{1}=90$. In 10a and 10c, $\sigma=0.4$ while in $10 \mathrm{~b}$ and $10 \mathrm{~d}, \sigma=0.8$.

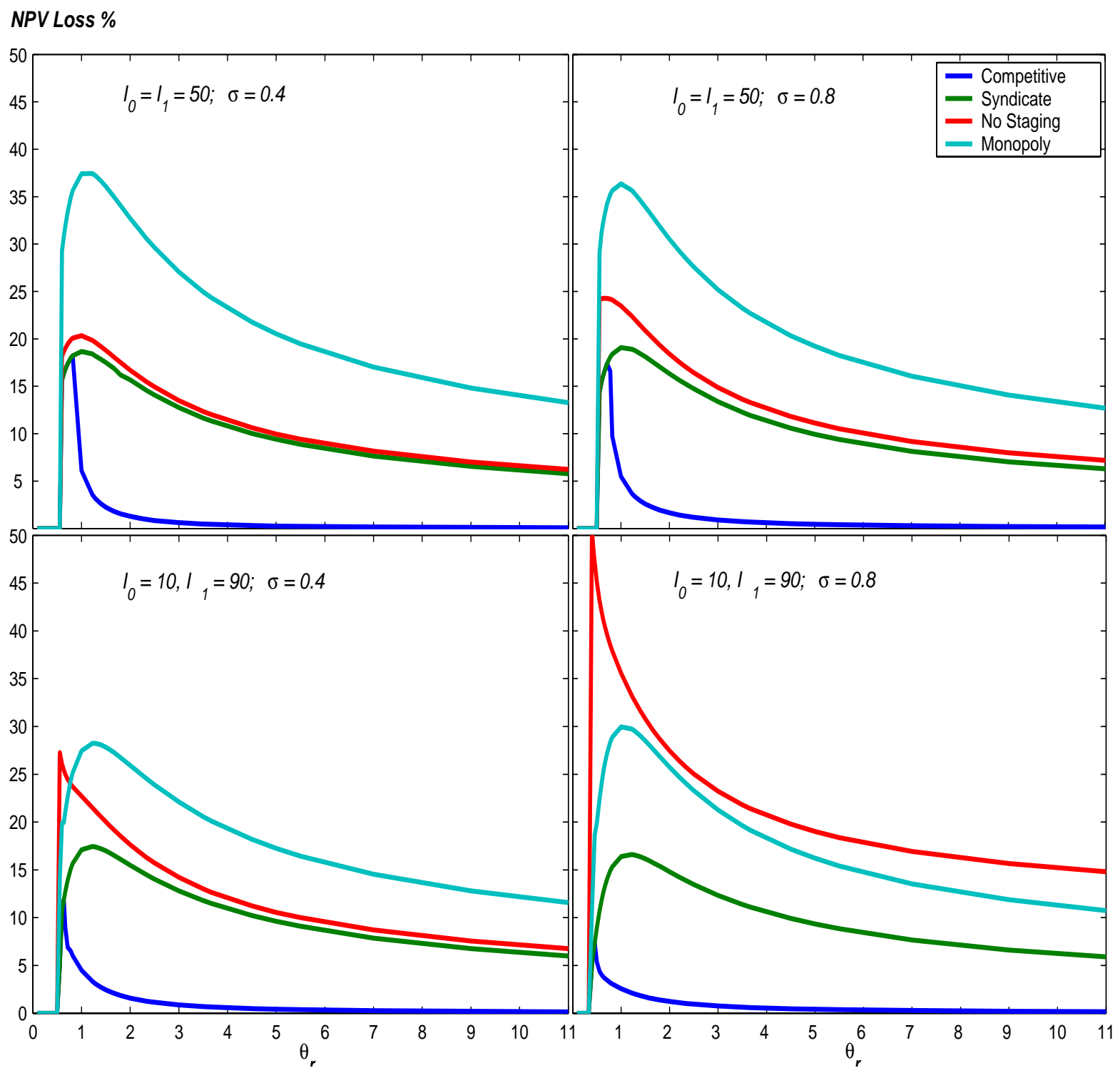

